Hydrol. Earth Syst. Sci., 21, 4495-4516, 2017

https://doi.org/10.5194/hess-21-4495-2017

(c) Author(s) 2017. This work is distributed under

the Creative Commons Attribution 3.0 License.

\title{
Necessary storage as a signature of discharge variability: towards global maps
}

\author{
Kuniyoshi Takeuchi $^{1, \mathrm{a}}$ and Muhammad Masood ${ }^{2}$ \\ ${ }^{1}$ International Centre for Water Hazard and Risk Management (ICHARM), \\ Public Works Research Institute (PWRI), Tsukuba, 305-8516, Japan \\ ${ }^{2}$ Bangladesh Water Development Board (BWDB), Design Circle-1, Dhaka, Bangladesh \\ ${ }^{a}$ currently at: Iwakubo-cho 392-2, Kofu, Yamanashi 400-0013, Japan \\ Correspondence to: Kuniyoshi Takeuchi (takeuchi@yamanashi.ac.jp)
}

Received: 3 October 2016 - Discussion started: 12 October 2016

Revised: 11 July 2017 - Accepted: 27 July 2017 - Published: 11 September 2017

\begin{abstract}
This paper proposes the use of necessary storage to smooth out discharge variability to meet a discharge target as a signature of discharge variability in time. Such a signature has a distinct advantage over other statistical indicators such as standard deviation (SD) or coefficient of variation $(\mathrm{CV})$ as it expresses hydrological variability in human terms, which directly indicates the difficulty and ease of managing discharge variation for water resource management. The signature is presented in the form of geographical distribution, in terms of both necessary storage $\left(\mathrm{km}^{3}\right)$ and normalized necessary storage (months), and is related to the basin characteristics of hydrological heterogeneity. The signature is analyzed in different basins considering the Hurst equation of range as a reference. The slope of such a relation and the scatter of departures from the average relation are analyzed in terms of their relationship with basin characteristics. As a method of calculating necessary storage, the flood duration curve (FDC) and drought duration curve (DDC) methods are employed in view of their relative advantage over other methods to repeat the analysis over many grid points. The Ganges-Brahmaputra-Meghna (GBM) basin is selected as the case study and the BTOPMC hydrological model with Water and Global Change (WATCH) Forcing Data (WFD) is used for estimating FDC and DDC. It is concluded that the necessary storage serves as a useful signature of discharge variability, and its analysis could be extended to the entire globe and in this way seek new insights into hydrological variability in the storage domain at a larger range of scales.
\end{abstract}

\section{Introduction}

Storage is the only means to smooth out discharge variability to meet targets for flood and drought management. Necessary storage depends on discharge variation, flood control targets, and water use targets. By fixing flood control and water use targets, necessary storage depends only on discharge variability and serves as a signature of discharge variability expressed in human terms, which directly conveys the sense of the difficulty or ease of controlling discharge for water resource use. For this reason, such a signature has a distinct advantage over other statistical indicators of variability such as standard deviation (SD) or coefficient of variation $(\mathrm{CV})$. Besides, by plotting the signature in a geographical map, hydrological variability in time and space can be compared with the geographical distribution of hydrological (including geophysical and geographical) heterogeneity over a basin such as hydro-meteorological, topographical, geological, pedological, vegetation, and land-use conditions. This paper is the first attempt to look at how hydrological variability compares with the signature, i.e., necessary storage, through its absolute volume $\left(\mathrm{km}^{3}\right)$ or its normalized form (months) divided by a local long-term mean discharge, to get new insights into the factors controlling the relationship between hydrological variability and hydrological heterogeneity. 


\subsection{Objectives}

This paper has three objectives. One is to propose necessary storages to smooth out discharge variation during floods and droughts as a new or alternative indicator or a signature of discharge variability in time and to compare it with standard variability indices such as SD and CV. Another is to present the geographical distribution of this signature and explore how the signature is related to the various hydrological heterogeneities of a basin. The last objective is to introduce an efficient methodology to calculate necessary storage at all grid points of a basin to perform geographical analysis using the flood duration curve and drought duration curve (FDCDDC) method. These objectives are elaborated below.

\subsubsection{Necessary storage as a signature of discharge variability in time}

Necessary storage to smooth out the variation of flow in time to control hazards and utilize resources depends on the variation of flow, flood channel capacity and the target level of water use. While flood channel capacity and the target water use are socio-economic parameters varying with societal needs for water and the environment, flow variation depends on natural hydrological phenomena of a basin over time and space. Therefore, if socio-economic targets are fixed at certain levels, necessary storage can be used as a signature of natural flow variability. While flow variability is very often described by the SD or the CV of discharge time series, its physical meaning is not necessarily clear in human terms. On the other hand, necessary storage has a concrete meaning that can be directly related to the physical size of a reservoir necessary for flood and drought management. Necessary storage is a necessary physical volume of storage space for flood control or volume of water stored for drought management in order to keep outflow downstream at a certain level. In this paper, we propose the use of necessary storage as a signature of hydrological variability in time and try to relate it to the hydrological heterogeneity of a basin over time and space.

Hydrological heterogeneity has been studied by many researchers such as Wood et al. (1988) in terms of scale effects, Creager et al. (1945) in terms of extremes, and Blöschl et al. (2013) in terms of predictability. This paper extends such analyses to water resource manageability in terms of necessary storage to smooth out hydrological variation as an integrated signature.

Blöschl et al. (2013) proposed six runoff signatures that determine runoff variability, namely, annual runoff, seasonal runoff, flow duration curve, low flow, floods and hydrographs. They are indeed important indicators of river runoff phenomena, especially for analytical diagnosis on flow prediction. On the other hand, for flood control and water supply, managers would be more interested in integrated information that indicates water resource manageability. For that purpose, necessary storage to smooth out discharge variation into given levels of constant flow can be an informative indicator. Necessary storage is an integrated result of hydrological variation that reflects short- and long-term means; daily, seasonal and long-term patterns of variation; extremes, duration or persistence characteristics, and frequencies or periodicities; and available flood channel capacity, necessary water withdrawal, etc. It is therefore truly an integrated signature of discharge variability and an integrated indicator of manageability of discharge variation.

\subsubsection{Geographical mapping of necessary storage}

In order to analyze necessary storage as a signature of discharge variability in relation to hydrological heterogeneity in a basin, it is essential to plot the signature in geographical distribution maps. For this purpose, necessary storage is calculated not only along the main streams in a river basin, as is often practiced for reservoir design, but also at all grid cells over a widespread area where the stream networks are formed. It is areal information rather than point information. This calculation method can help water resource managers grasp regional discharge variability of floods and droughts in natural conditions with relative ease.

In this paper, however, calculated necessary storage cannot be interpreted as actual necessary storage for reservoir design and water management since the actual status of channel capacity and water withdrawal at a given location are treated as given parameters and not accounted for in the calculation. It is only a signature of discharge variability in the unit of necessary storage to maintain certain constant flow levels for flood control and water use in downstream areas. As certain flow levels, the mean annual flow or some percentage of it is used to help users to easily imagine the assumptions.

Geographical maps of necessary storage for flood and drought will be compared with geographical maps of elevation, precipitation, land use and land cover, discharge and its standard deviation and coefficient of variation. In addition, using scatter diagrams, the hydrological heterogeneity will be analyzed by looking into the slope of the average relation and the scatter of departures from the average relation of necessary storages to catchment area $A, \mathrm{SD}$ and $\mathrm{CV}$ of various sub-basins. Such a departure will be related to the hydrological characteristics of different basins. It will be the first step of looking into the relation between necessary storage and hydrological heterogeneity including land cover and other geographical conditions.

\subsubsection{Flood duration curve and drought duration curve (FDC-DDC) to calculate necessary storages}

In order to produce a spatial distribution map of necessary storage of a large basin, and eventually of the globe, it is necessary to employ an efficient methodology for calculating necessary storage. There are various ways of calculating necessary storage depending on various conditions and ob- 
jectives. The most widely known is the mass curve method developed by Rippl (1883), which has been used over a century as a standard methodology of calculating necessary storage with a given constant target water use (Klemes, 1979). For more complicated target water use patterns, a simulation method was introduced and extensively studied by the Harvard Water Program in the 1950s (Maass et al., 1962). The former initiated epoch making research movements on storage analyses of range (Hurst, 1951; Feller, 1951; Moran, 1959), and the latter on streamflow synthesis (Thomas and Fiering, 1962; Mandelbrot and Wallis, 1969; Valencia and Schaake, 1973).

In this paper, instead of those methods, the flood duration curve and drought duration curve (FDC-DDC) method was used as it is relatively easy to calculate necessary storage under any given constant level of target release and better suited for calculating necessary storage at many grid points over a space for areal mapping of reservoir storage. Such relative ease comes from two simplifications, a stationarity assumption and a short-term focus. The stationary assumption is inherent to the use of intensity-duration-frequency curves and its estimation accuracy is bounded by the available length of data. The short-term focus on an annual smoothing rather than inter-annual smoothing is in sharp contrast to a longterm asymptotic focus of the range analyses. It is unacceptable in general for water resource management, but is used here for simplicity as an example to introduce the indicator for eventual global presentation and analyses. The main theory of the range analysis is briefly introduced in Sect. 2.3.2. The drought duration curve (DDC) was first proposed by Kikkawa and Takeuchi in the 1970s (Kikkawa and Takeuchi, 1975; Takeuchi and Kikkawa, 1980). The DDC was shown to be useful for reservoir operation (Takeuchi, 1986), and by adding the flood duration curve (FDC), the FDC-DDC was also proven to be useful for hydrological statistics and classification (Takeuchi, 1988).

\subsection{The case study area}

This paper takes a case study approach to demonstrate the proposed use of necessary storage as an indicator of discharge variability. For that purpose, the GangesBrahmaputra-Meghna (GBM) basin was selected as it has heterogeneous geographical conditions and is large enough to eventually extend the analyses into the globe. Figure 1 depicts the Ganges-Brahmaputra-Meghna (GBM) basin (Pfly, 2011). According to FAO AQUASTAT (2011), the total basin area is about 1.7 million $\mathrm{km}^{2}$, shared by India (64\%), China (18\%), Nepal (9\%), Bangladesh (7\%) and Bhutan (3\%). It is the world's third largest freshwater outlet to the oceans. Figure 2 shows the land cover distribution which well reflects the elevation and precipitation depicted in Fig. 3a and b, respectively. The land cover data were collected from the Global Land Cover by National Mapping Organizations (GLCNMO) which was prepared by using MODIS data with remote sensing technology (Tateishi et al., 2014). The GLCNMO classifies the status of land cover of the whole globe into 20 categories based on the Land Cover Classification System (LCCS) developed by FAO. The elevation data of Fig. 3a are acquired from HydroSHEDS, which is derived from remote sensing data of the Shuttle Radar Topography Mission (SRTM) at $3 \operatorname{arcsec}(90 \mathrm{~m})$ resolution during an 11-day mission in February 2000 (Lehner et al., 2006). The mean precipitation map of Fig. $3 \mathrm{~b}$ is created from the daily rainfall and snowfall data from the Water and Global Change (WATCH) Forcing Data (WFD) set to be explained in Sect. 3.1.1.

These data would be useful to relate the geographical distribution of necessary storage indicators to the hydrological heterogeneity of a basin. All geographical maps except Fig. 1 indicate the borders of the Ganges, the Brahmaputra and the Meghna in thick black lines, the selected inner sub-basins in thin black lines and national boundaries in white lines.

As Fig. 3b indicates, the Ganges basin is characterized by a large spatial variation of precipitation that causes water scarcity in the western Ganges and water excess in the southeast. The Ganges is a snowmelt-fed river which is regulated by 75 artificial dams (Lehner et al., 2011). The Brahmaputra basin is characterized by high precipitation in eastern India and a large amount of snow in the upstream that provides a huge volume of discharge to the river. On the other hand, the Meghna is a comparatively smaller, rain-fed, and relatively flashier river. The basin contains the world's top two highest precipitation (about $12000 \mathrm{~mm} \mathrm{yr}^{-1}$ ) areas: Mawsynram and Cherrapunji (Masood and Takeuchi, 2015b).

The GBM river basin contains about a tenth of the world's population. As the population is still steadily increasing, the usage of water is increasing rapidly to meet municipal, agricultural and industrial water demands. In addition, the basin is also recognized as one of the areas most prone to waterborne natural hazards, floods and droughts in the world, which threaten a large number of the population each year. Therefore, the management of water resources plays a crucial part in ensuring the sustainability of the region.

\subsection{Structure of the paper}

In Sect. 2, the methodology is presented, namely, the flood and drought duration curves, FDC-DDC, in Sect. 2.1 and the method of calculating necessary storage using FDC-DDC in Sect. 2.2. The comparison of this method with the standard mass curve method and the analysis of spatial distribution of necessary storage in contrast to analysis of asymptotic temporal nature several decades ago are also discussed in Sect. 2.3. In Sect. 3, application of the methodology to the case study area, the GBM basin, is described. Also described are the necessary precipitation and temperature data set, WATCH Forcing Data, and the BTOPMC hydrological model to translate them to discharge data. Section 4 presents application results and discusses their implications. 


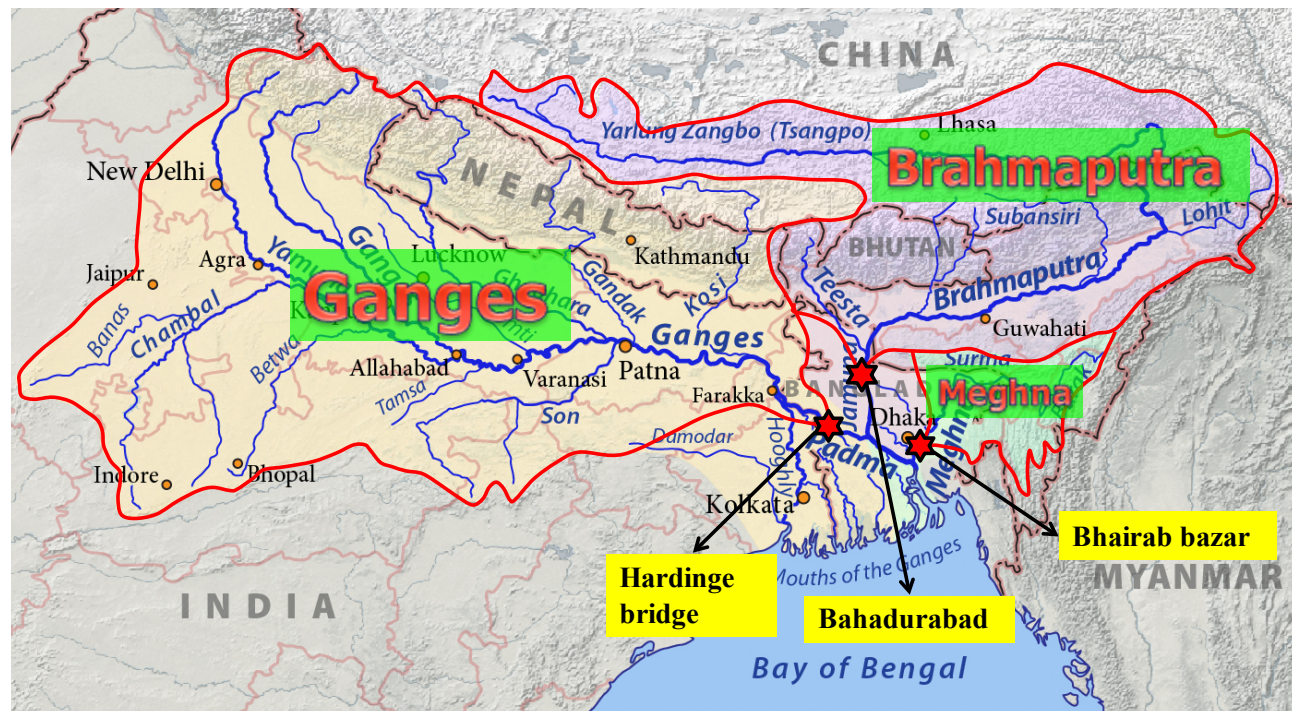

Figure 1. The Ganges-Brahmaputra-Meghna (GBM) basin (modified from Pfly, 2011).

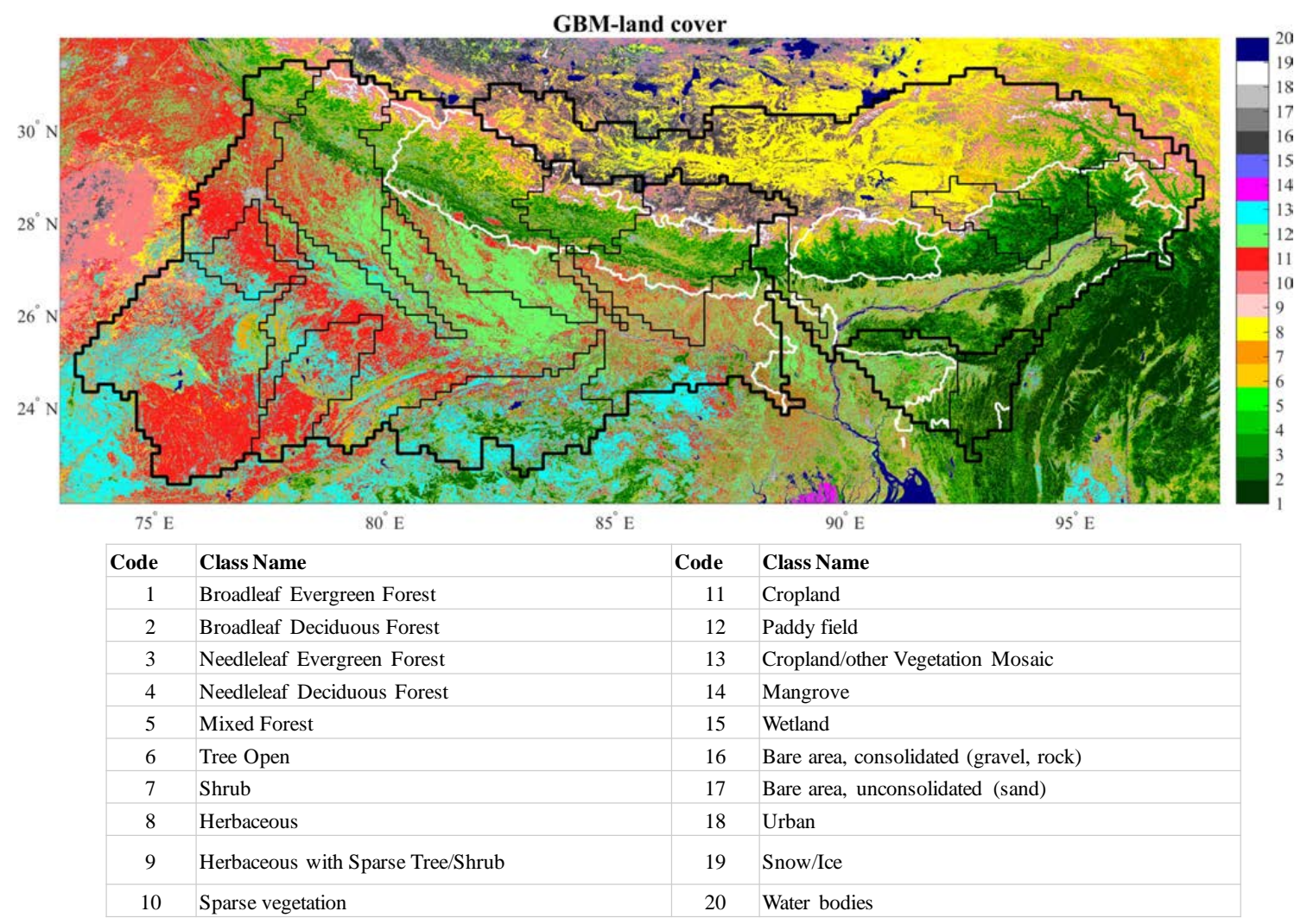

Figure 2. Land cover of the GBM basin from GLCNMO (Tateishi et al., 2014).

Discussed in Sect. 4.1 are geographical distribution of necessary storage, in Sect. 4.2 the relation between necessary storage and catchment characteristics such as area $A$ and SD and $\mathrm{CV}$ of discharge, and in Sect. 4.3 their zoom-up rela- tions in the selected 12 sub-basins. Finally, Sect. 5 presents conclusions. 

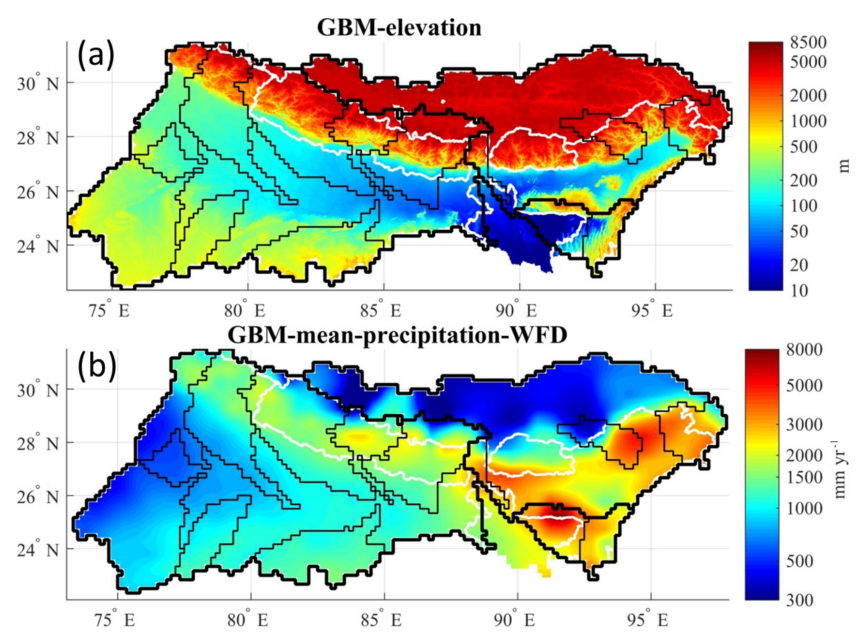

Figure 3. The (a) elevation and (b) precipitation distributions of the GBM basin.

\section{Methodology}

This chapter first introduces the methodology of calculating FDC-DDC in Sect. 2.1, which basically follows a similar notation used in Takeuchi (1988) with slight modifications to a simpler form neglecting seasonal parameter $\tau$. Section 2.2 introduces the methodology of calculating necessary storage which follows the procedure originally introduced in Kikkawa and Takeuchi (1975) and in Takeuchi (1986) but in a more elaborated way. Finally, in Sect. 2.3, other discussions related to this paper will be introduced, including the relation between the FDC-DDC method and the traditional mass curve method (Takeuchi and Kikkawa, 1980) and the discussion of the Hurst formula (Hurst, 1951).

\subsection{Flood duration curve (FDC) and drought duration curve (DDC)}

Both FDC and DDC are basically intensity-durationfrequency (IDF) curves of discharge time series, but not on actual discharge data but on their moving averages. Let $x_{t}$ denote any hydrological variable at time $t$ and random variable $X(m)$ denote the annual maximum of moving averages of any $x_{t}$ over $m$ days starting any day $t_{1}$ of a certain year. Its quantile value for exceedance probability $\alpha$ denoted by $f_{a}(m)$ is defined as a flood duration curve. Similarly, random variable $X^{\prime}(m)$ denotes the annual minimum of moving averages of $m$ days starting from any day belonging to the year. Its quantile value for non-exceedance probability $\beta$ denoted by $f_{\beta}^{\prime}(m)$ is defined as a drought duration curve. Namely,

$$
\begin{aligned}
X(m) & =\max _{t_{1} \in a \text { certain year }} \frac{1}{m} \sum_{t=t_{1}}^{t_{1}+m-1} x_{t}, \\
X^{\prime}(\mathrm{m}) & =\min _{t_{1} \in a \text { certain year }} \frac{1}{m} \sum_{t=t_{1}}^{t_{1}+m-1} x_{t},
\end{aligned}
$$

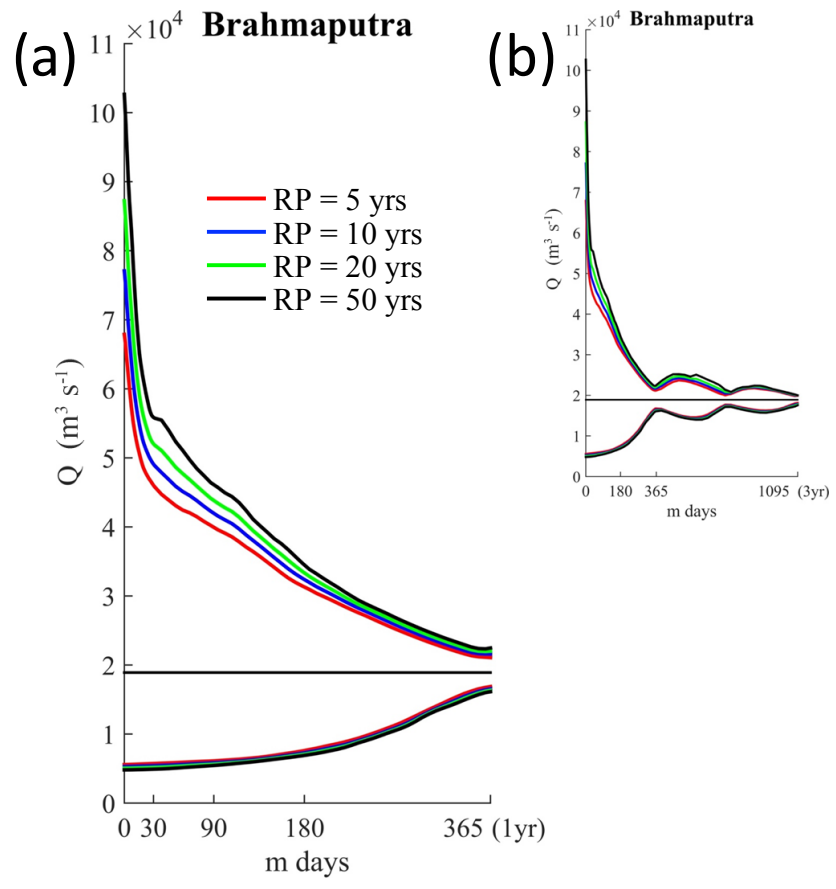

Figure 4. FDC-DDCs of the Brahmaputra River at Bahadurabad station (a) for 1 year and (b) for 3 years. The discharge data were simulated by BTOPMC with WFD.

$\operatorname{Prob}\left(X(m) \geq f_{a}(m)\right) \leq a$,

$\operatorname{Prob}\left(X^{\prime}(m) \leq f_{\beta}^{\prime}(m)\right) \leq \beta$.

In this study, hydrological variable $x_{t}$ is discharge and the quantiles of flood duration curve (FDC) $f_{a}(m)$ and drought duration curve (DDC) $f_{\beta}^{\prime}(m)$ in Eqs. (3) and (4) were estimated by fitting a generalized extreme value (GEV) distribution, where parameters were estimated by the maximum likelihood method for $\alpha$ and $\beta$ being $0.2,0.1,0.05$ and 0.02 , corresponding to 5-, 10-, 20- and 50-year return periods $(T)$. The GEV distribution Type-1, Gumbel distribution was used in this study as it was recommended for the major rivers in Bangladesh by Mirza (2002) and for relatively smaller data samples by Hirabayashi et al. (2013).

Figure 4a depicts the FDC and DDC of the Brahmaputra River at Bahadurabad station (Fig. 1). It shows for $m$ up to 1095 days or 3 years. The duration curves oscillate with duration time length reflecting the annual periodicity of the hydrograph. For higher return periods, the duration curves lay outside of the long-term mean discharge line, implying higher flood discharges and lower drought discharges. In this paper, however, as will be explained in Sect. 2.3.2, the portion for $m$ up to 365 days or 1 year, i.e., Fig. 4b, is used throughout the discussion to get a practical signature.

The duration curves are theoretically nothing but intensity-duration-frequency (IDF) curves, but practically they are considerably different. Ordinarily IDF curves are 
nearly exclusively used for design of storm drainage systems and accordingly concern precipitation on its high-intensity side for a rather short term such as several hours to a few days. On the other hand, the FDC-DDC applies precipitation, discharge, or any other time series not only on the highintensity side, but also on the low-intensity side. Also, the concerned time length or duration extends over months to multiple years.

In fact the original development of this duration curve was DDC rather than FDC for reservoir management during a drought and the idea was totally independent of IDF (Kikkawa and Takeuchi, 1975). Its central interest was the minimum discharge that can be expected for $m$ days in the future as the worst case scenario. Takeuchi (1986) applied the DDC to chance-constrained reservoir operation as DDC $f_{\beta}^{\prime}(m)$ indicates the average inflow that can be expected for any $m$ days in the future with the failure rate less than $\beta$. Later, the idea was extended to the flood side and FDC-DDC was developed as a means of classifying the persistence characteristics of regional hydrology, precipitation and discharge that serve as an indicator or a palm print of basin hydrology (Takeuchi, 1988).

\subsection{Necessary storage}

This section illustrates the detailed procedure of calculating necessary storage to smooth out discharge variations over time using FDC-DDC. In short, necessary storage is obtained as the largest inner rectangular area that just fits to the area surrounded by a duration curve, the target discharge level (such as the long-term mean) and the vertical axis at the origin. Necessary storage indicates the empty space necessary for flood control at the beginning of the flood season and the stored volume of water necessary for water supply at the beginning of the drought season with the failure rate indicated by the duration curves.

\subsubsection{Necessary storage to smooth out high flows (floods)}

Figure 5 depicts a schematic FDC-DDC of discharge at the dam site concerned.

1. Suppose at a time before the flood season, a flood manager considers how much flood control space he/she needs to smooth out all the high flows expected in the season.

2. Suppose the flood channel capacity or the target river discharge level is the long-term mean of river discharge EM in Fig. 5 (which may not be realistic but useful for simplicity to get a practical signature).

3. Suppose he/she chooses a return period of 20 years or a failure rate of 0.05 . Then he/she chooses a flood duration curve $f_{0.05}(\mathrm{~m})$.

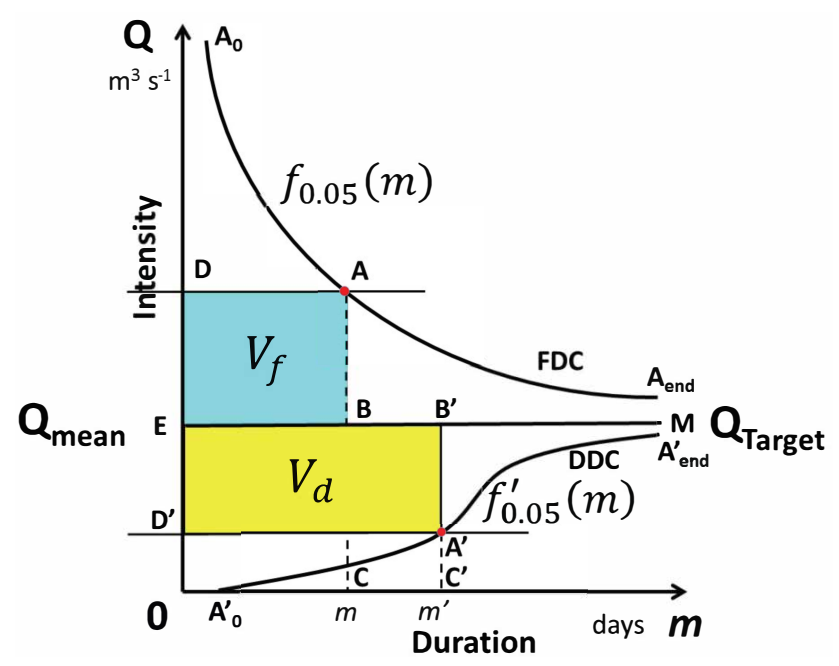

Figure 5. Schematic illustration of how to calculate necessary storages $V_{\mathrm{f}}$ and $V_{\mathrm{d}}$ to smooth out the hydrological variation to the longterm mean $Q_{\text {mean }}$ for flood control and drought management.

4. Suppose he focuses on point A on the FDC $f_{0.05}(m)$ where $m=50$ days.

5. Horizontal line DA passing through point A, namely $f_{0.05}(50)$, is the annual maximum average discharge per day over any 50 days starting from any date in any year that will be exceeded only with probability 0.05 . In other words, this level is the average flood discharge that the flood manager expects and likes to smooth out.

6. How much volume is the total flood discharge in those 50 days? It is simply $f_{0.05}(50) \cdot 50$, which is the area of rectangle ADOC.

7. Now, how much flood discharge can the river safely flow down, or what is the flood channel capacity? That is, he assumes a long-term average discharge indicated by line EB (on EM). The flood volume that can safely flow down is the area indicated by rectangle BEOC.

8. Therefore, the necessary storage capacity the flood manager needs to prepare for flood space before the flood season is $\mathrm{ADOC}-\mathrm{BEOC}=\mathrm{ADEB}$.

9. Now the flood manager has to consider the necessary storage space by moving point $\mathrm{A}$ all the way from the start to the end, in this case point $A_{0}$ to $A_{\text {end }}$, and identify the largest volume necessary for flood control. This can be expressed as

$$
V_{f_{\alpha}}=\max _{m} m \cdot f_{\alpha}(m) .
$$

In this study, the interest duration is limited to a year, neglecting the need for multi-year smoothing. In reality, an over-year storage is very important and in many practical 
cases critical, especially in arid/semi-arid zones, but as a signature to be examined eventually by a global map, we first concentrate on intra-annual smoothing for simplicity. Necessary storage for inter-annual smoothing increases with time, eventually to infinity, as Hurst (1951) showed, which is briefly discussed in Sect. 2.3.2.

By this simplification, necessary storage can be expressed in a narrative way as the area of the largest rectangle that just fits to a right triangle surrounded by the flood duration curve, the channel capacity line, and the vertical axis of the origin.

\subsubsection{Necessary storage to smooth out low flows (droughts)}

A similar discussion for necessary storage for drought management will follow below. Again Fig. 5 will be used for explanation.

1. Suppose a drought manager considers how much water is necessary to be stored before the dry season starts.

2. Suppose he/she is obliged to keep supplying water equal to the long-term mean of river discharge, which is indicated by line EM.

3. Suppose he/she chooses a return period of 20 years or a failure rate of 0.05 . Then he/she chooses a drought duration curve $f_{0.05}^{\prime}\left(\mathrm{m}^{\prime}\right)$.

4. Suppose he/she focuses on point $A^{\prime}$ on the DDC $f_{0.05}^{\prime}\left(m^{\prime}\right)$ where $m^{\prime}=150$ days.

5. Horizontal line D'A' passing through point A', namely $f_{0.05}^{\prime}(150)$, is the annual minimum average discharge per day over any 150 days in a year, which will fail only with probability 0.05 . In other words, this level is the average low flow over the next 150 days, which the drought manager expects and likes to go around by augmentation from reservoir storage.

6. How much volume is the total discharge he can expect in those 150 days? It is simply $f_{0.05}^{\prime}(150) \cdot 150$, which is the area of rectangle A'D'OC'.

7. Now, how much water should be released to meet the water supply target during the next 150 days? The drought manager is obliged to supply the long-term average discharge indicated by line EB'. The necessary volume to be released to meet the target is indicated by the area of rectangle B'EOC'.

8. Therefore the necessary reservoir storage the drought manager needs to prepare for drought management before the dry season starts is A'D'OC'$\mathrm{B}^{\prime} \mathrm{EOC}^{\prime}=\mathrm{A}^{\prime} \mathrm{D}^{\prime} \mathrm{EB}$ '.

9. Now the drought manager has to consider the necessary storage to be reserved for augmentation by moving

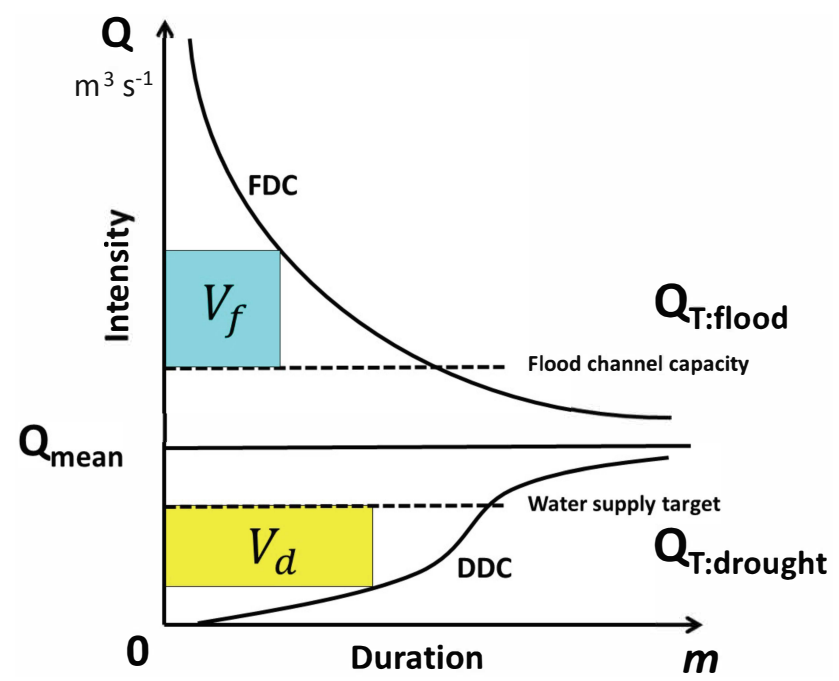

Figure 6. Schematic illustration of how to calculate necessary storages $V_{\mathrm{f}}$ and $V_{\mathrm{d}}$ to smooth out the hydrological variation to $3 Q_{\text {mean }}$ for flood control and $0.5 Q_{\text {mean }}$ for drought management.

point A' all the way from the start to the end, in this case point $\mathrm{A}_{0}{ }_{0}$ to $\mathrm{A}^{\prime}$ end, and identify the largest volume necessary for drought management. This can be expressed as

$$
V_{d_{\beta}}=\max _{m^{\prime}} m^{\prime} \cdot f_{\beta}^{\prime}\left(m^{\prime}\right) .
$$

Again in this study, the range of the averaging time length $m$ was limited to 365 days or a year. This assumption is more critical for drought management than for flood management as a multiyear drought is frequently experienced and a serious concern in many arid and semi-arid nations. But as a practical signature, the time length of a year is selected. Nevertheless, the methodologies themselves, i.e., Eqs. (5) and (6), are valid for any $m$, and can work for calculating necessary storage for a multiyear drought regardless of its length.

\subsubsection{With arbitrary target releases}

Instead of assuming the target releases to be always equal to the long-term mean, the targets can be set to the real flood channel capacity and the safe yield level of water supply as seen in Fig. 6. In such cases, the line of long-term mean EM in items 2 and 7 of the procedures above should be replaced by the channel capacity for flood control and the target water supply for drought management. Resultant necessary storage $V_{\mathrm{f}}$ for flood control and $V_{\mathrm{d}}$ for drought management can be calculated as in Fig. 6. As mentioned above, however, this study uses the long-term mean to get a signature for simplicity. 


\subsubsection{Expressions in $\mathrm{km}^{3}$ and months}

Necessary storages $V_{\mathrm{f}}$ and $V_{\mathrm{d}}$ at each grid point may be expressed in $\mathrm{km}^{3}$ and in general are expressed as $V_{\mathrm{km}^{3}}$. However, the dominant areal distribution of necessary storage $V_{\mathrm{km}^{3}}$ would be similar to the distribution of catchment area because as catchment area increases, discharge increases in general and so does magnitude of flow variation, which would result in the increase in necessary storage to smooth out the variation. In order to better analyze necessary storage in relation to hydrological heterogeneity in a basin, a normalized signature $V_{\text {month }}$ expressed in months may be used by dividing the necessary storage volume $V_{\mathrm{km}^{3}}$ by local long-term mean discharge $Q_{\text {mean }}\left(\mathrm{m}^{3} \mathrm{~s}^{-1}\right)$ expressed in $\mathrm{km}^{3}$ months ${ }^{-1}$, namely,

$V_{\text {month }}=V_{\mathrm{km}^{3}} / Q_{\text {mean }}$.

Value $V_{\text {month }}$ indicates an average residence or renewal time of water in the reservoir whose capacity is equal to the necessary storage and assumed full all the time. This is free from the mean annual flow and reflects other factors of hydrological variability.

\subsection{Related discussions on necessary storage}

\subsubsection{Relation between the FDC-DDC method and the standard mass curve method}

The methodology presented in Sect. 2.2 is considerably different from the standard mass curve method originally proposed by Rippl (1883) and widely used in engineering fields (Klemes, 1979). The major difference is its assignment of a return period. The original mass curve method does not translate the original hydrograph into the frequency domain or an intensity-duration-frequency (IDF) curve which has the same return period along a particular IDF curve for any duration. In reality there is no hydrograph that always has the same return period at any time for any duration but a mixture of many different high- and low-flow episodes with different return periods. As the mass curve method utilizes actual hydrological time series, the assignment of a return period or rate of failure is not necessarily in a strict manner. The total negative run sum or negative run length is often used to identify the return period which largely depends on the length of time on which an analysis focuses. The FDC-DDC method is free from such selection of length of time and the practical differences are in fact minor, as shown by Takeuchi and Kikkawa (1980).

\subsubsection{Necessary storage in the temporal domain and in the spatial domain}

Research on range will be briefly reviewed in this section as it is the analysis of necessary storage in a long-term asymptotic behavior, while this paper focuses, by contrast, on short- term spatial characteristics. Hurst (1951) considered necessary storage as "adjusted range" $R_{\mathrm{n}}$ to keep long-term mean flow $Q_{\mathrm{m}}=\bar{x}_{n}$ for $n$ consecutive time periods as follows:

$S_{t}=S_{t-1}+\left(x_{t}-\bar{x}_{n}\right)$,

$R_{n}=\max _{t=1, \ldots, n} S_{t}-\min _{t=1, \ldots, n} S_{t}$,

where $x_{t}$ is discharge at time $t, S_{0}=0, \bar{x}_{n}=\frac{1}{n} \sum_{t=1}^{n} x_{t}, s_{n}=$ $\sqrt{\frac{1}{n-1} \sum_{t=1}^{n}\left(x_{t}-\bar{x}_{n}\right)^{2}}$,

and found from his Nile study that

$R_{n}^{*}=R_{n} / s_{n} \propto n^{H}$,

where $R_{n}^{*}$ is named the "rescaled adjusted range" and $H$, the Hurst coefficient, was $\cong 0.72$.

This indicates that necessary storage $R_{\mathrm{n}}$ increases limitless with time length $n$ to be considered and is proportional to $s_{n}$ as

$R_{\mathrm{n}} \propto s_{n} n^{H}$

or in a different form by dividing both sides by the long-term mean $\bar{x}_{n}$ as

$R_{\mathrm{n}} / \bar{x}_{n} \propto C_{\mathrm{v}} n^{H}$

where $C_{\mathrm{v}}=s_{n} / \bar{x}_{n}$ is the coefficient of variation of discharge.

$R_{\mathrm{n}} / \bar{x}_{n}$ is necessary storage normalized by the long-term mean flow which has the unit "time" and may be called normalized necessary storage or a mean residence time or a mean renewal time of water storage $R_{\mathrm{n}}$ of the reservoir. Equations (9) and (10) provide the theoretical background for $V_{\mathrm{km}^{3}}$ and $V_{\text {month }}$ of Eq. (7); namely, $V_{\mathrm{km}^{3}}$ is proportional to $s_{n}$ and $V_{\text {month }}$ is to $C_{\mathrm{v}}$.

In this study, the length of available discharge data is 22 years (1980-2001) as explained in Sect. 3.1, and there is no way of considering infinite length behavior. But, in theory, regardless of the choice of expression, formula Eq. (8) says that necessary storage $R_{\mathrm{n}}$ or its normalized form $R_{\mathrm{n}} / \bar{x}_{n}$ increases with time periods $n$ to be considered. It is a serious fact in terms of water resource management if long-term mean $\bar{x}_{n}$ is indeed the target of water supply or flood channel capacity, and it should be kept for a very long time such as over many years. But, in reality, it is not usually the case because flood control and water supply targets do not usually require all fluctuations removed and keep the flow constant to the long-term mean. People living along rivers are settled in a way to safely accommodate several-year return periods of natural floods and droughts; namely, they can accommodate, without having storage reservoirs, floods far above the longterm mean discharge and can live with water use far below the long-term mean flow. It means that necessary smoothing of discharge variation over time is usually much shorter than multiple years. Especially in humid regions, particularly in 
small basins with limited reservoir capacity, the target water smoothing is often for a short term in practice.

This paper therefore looks into spatial distribution of necessary storage with a limited temporal scale, namely, a year or $m \leq 365$ days. Admitting some contradiction in approach, the target water control level is still assumed as the longterm mean discharge to make the discussion simple. Note again that the objective of this paper is not reservoir design for construction, but introduction of a signature of discharge variability in relation to hydrological heterogeneity.

Based on such assumptions, necessary storage is calculated at each grid cell of a basin, and instead of focusing on their temporal behavior, their spatial behavior will be examined. The geographical distribution of necessary storage will be discussed in Sect. 4.1, and the scale effects of normalized necessary storage will be discussed in Sect. 4.2.

\section{Application}

In order to demonstrate an example of the spatial distribution of FDC-DDC necessary storage, this study presents a case study in the Ganges-Brahmaputra-Meghna (GBM) basin. As the objective of the case study is methodological demonstration, no other cases are analyzed.

\subsection{Data used}

The necessary discharge data at all internal grid points of the GBM basin for the case study were obtained by model simulation with the reanalysis precipitation and radiation data and the observed discharge data for calibration as described below.

\subsubsection{Precipitation and temperature data used}

The precipitation and temperature data used over the GBM basin for the input to the distributed hydrological model were the WFD (Weedon et al., 2011) for the period of 1 January 1980 to 31 December 2001. The WFD is the data set based on the 3-hourly ERA-40 reanalysis product of the European Centre for Medium Range Weather Forecasting (ECMWF) developed in the European Union WATCH project (www.eu-watch.org). ERA-40 was derived from successive short-term integrations of a general circulation model (GCM) that assimilated various satellite data along with atmospheric soundings and land-sea surface observations. The one-degree resolution ERA-40 reanalysis data were interpolated into the half-degree resolution on the Climate Research Unit of the University of East Anglia (CRU) land mask. Average temperature and the average diurnal temperature range from CRU TS2.1 gridded observations were used to remove monthly bias and lack of climatic trends which existed in the $2 \mathrm{~m}$ temperature product of ERA-40. After bilinear interpolation, elevation correction on temperature data was done via an environmental lapse rate. Monthly bias of precipitation data was corrected by using the CRU number of "wet days", version four of the Global Precipitation Climatology Centre (GPCCv4) precipitation totals and ERA-40 rainfall-snowfall proportion. FLUXNET data (https://fluxnet.ornl.gov/) were used to validate the data. For details on WFD data generation, see Weedon et al. (2010, 2011).

\subsubsection{Discharge data used}

Using the forcing data above, the discharge data at all grid points of the GBM basin were created by model simulation using a distributed hydrological model, BTOPMC. The model and the model setup and verification are described below in Sect. 3.2 and 3.3. For calibration of the model, the discharge data at Hardinge Bridge, Bahadurabad and Bhairab Bazar, three outlets of the Ganges, Brahmaputra and Meghna, were constructed from the observed daily water level data, provided by the Processing and Flood Forecasting Circle, Bangladesh Water Development Board (BWDB), by using the rating equations developed by the Institute of Water Modelling (IWM, 2006) and Masood et al. (2015c).

\subsection{Hydrological model to obtain discharge data}

A physically based distributed hydrological model, BTOPMC, was used for simulating runoff. The BTOPMC (Block-wise use of TOP model with the Muskingum-Cunge method) was developed at the University of Yamanashi and ICHARM, PWRI, Japan (Takeuchi et al., 1999, 2008; Ao et al., 1999, 2003, 2006; Hapuarachchi et al., 2008). It is an extension of TOPMODEL (Beven and Kirkby, 1979) to apply to large basins. The extension is made by introducing the effective contributing area concept; that is, the discharge generation from a grid cell in a large basin is not necessarily contributed by its whole upstream catchment, but only by a portion of it. Based on this concept, the original topographical index is modified by replacing upstream catchment area $a$ by effective catchment area $a f(a)$ and transmissibility coefficient $T_{0}$ by dischargeability $D_{0}$ (Takeuchi et al., 2008). For flow routing, basically the Muskingum-Cunge (MC) method (Cunge, 1969) is adopted to take diffusive factors into account. But a modification was made to conserve the continuity of water volume at each segment of the river reach (Masutani and Magome, 2009). The BTOPMC has been applied in many river basins throughout the world, including poorly gauged basins utilizing globally available data, and found that the BTOPMC can simulate river discharges quite well, especially in warm humid regions (Takeuchi et al., 2013; Magome et al., 2015; Gusyev et al., 2016).

\subsection{Model setup and verification}

The BTOPMC model was set up for simulations of the WFD data set at the 10 arc-min grid (approximately $20 \mathrm{~km}$ grid resolution) using DEM data derived from HydroSHEDS. The model setup procedure followed the work by Masood and 

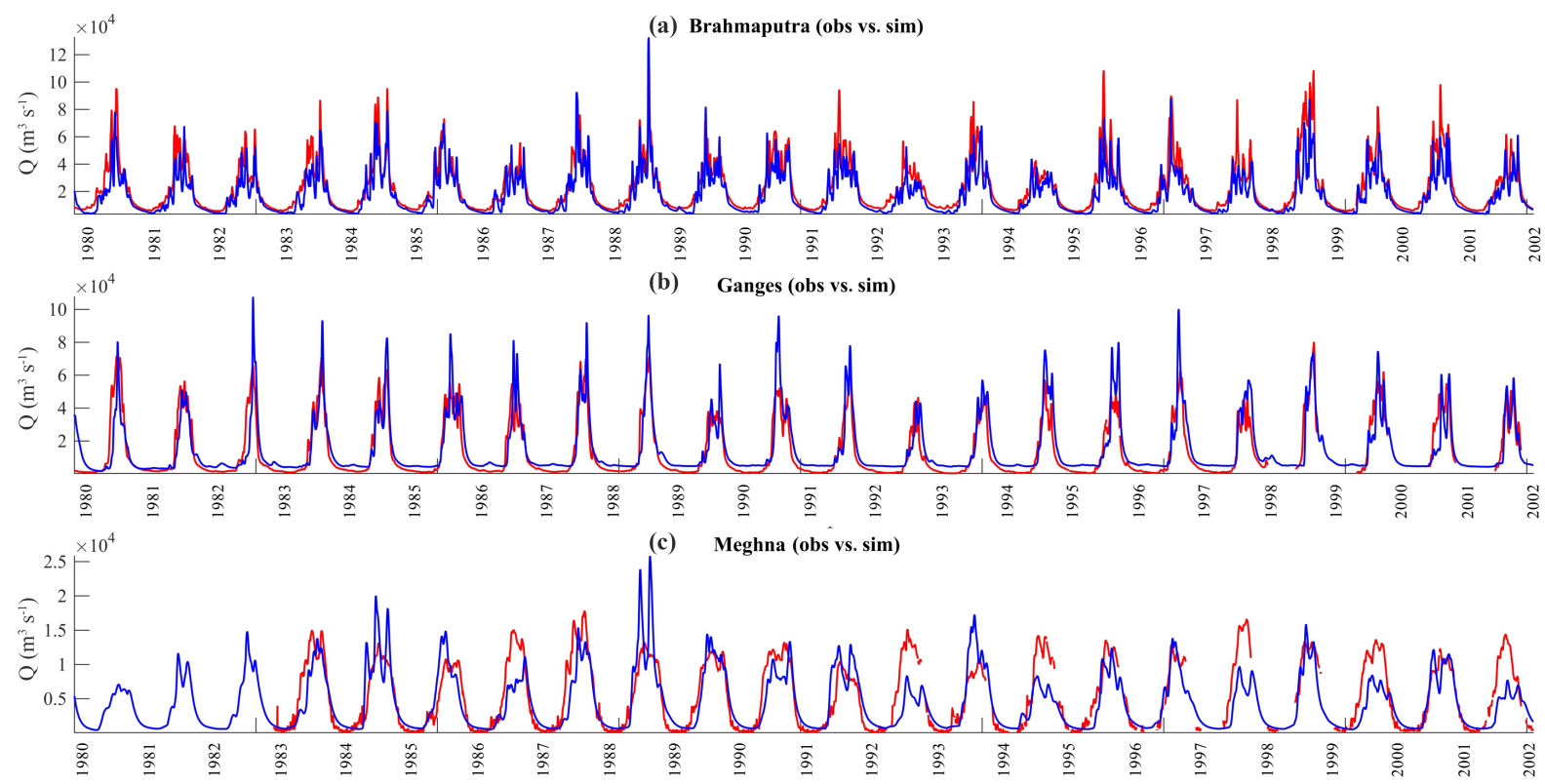

Figure 7. Comparisons of the observed (red) and BTOPMC simulated (blue) discharges at (a) the Bahadurabad, the Brahmaputra, (b) Hardinge Bridge, the Ganges, and (c) Bhairab Bazar, the Meghna. The calibration period is 1980-1990. Precipitation data used are WATCH Forcing Data (WFD). See Table 1 for the Nash-Sutcliffe efficiency.

Takeuchi (2015a), although their study used a hydrological model, instead of BTOPMC, H08 (Hanasaki, 2008).

The calibration period was from 1980 to 1990 (11 years) and verification was from 1991 to 2001 (11 years). Most of the BTOPMC parameters are related to and identifiable by physical features of land cover and soil as specified by Takeuchi et al. (2008). For three particular parameters, decay factor $(m)$, drying function $(\alpha)$ and Manning's roughness coefficient $\left(n_{0}\right)$ were determined by calibration examining all the combinations of three parameters in eight different values selected from their feasible physical ranges described in Takeuchi et al. (2008). A total of $8^{3}(=512)$ simulations were conducted. The identified parameters are listed in Table 1.

Figure 7 plots the daily hydrograph comparisons at the outlets of three river basins with the corresponding daily observations for both calibration and validation periods. Model performance was evaluated by comparing observed and simulated daily streamflows by the Nash-Sutcliffe efficiency (NSE) (Nash and Sutcliffe, 1970), the optimal objective function for assessing the overall fit of a hydrograph (Sevat and Dezetter, 1991). The obtained NSEs range from 0.80 to 0.91 for three basins (Table 1). Statistical indices suggest that the overall model performance is satisfactory.

The simulated daily discharge data sets at all grid cells of the GBM basin were obtained. Figure 8a shows the distribution of annual mean discharge $Q_{\text {mean }}\left(\mathrm{m}^{3} \mathrm{~s}^{-1}\right)$; Fig. $8 \mathrm{~b}$, the distribution of the standard deviation $s$ (SD) of daily discharge $\left(\mathrm{m}^{3} \mathrm{~s}^{-1}\right)$; and Fig. 8c, the distribution of the coefficient of variation $C_{v}(\mathrm{CV})$ of the daily discharge. The necessary storage was also calculated by the DDC-FDC method

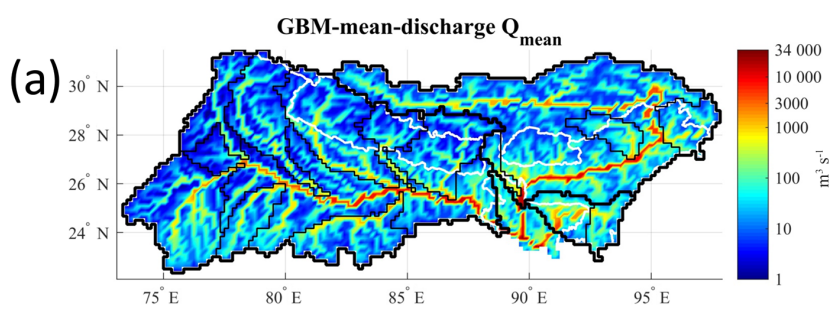

(b)
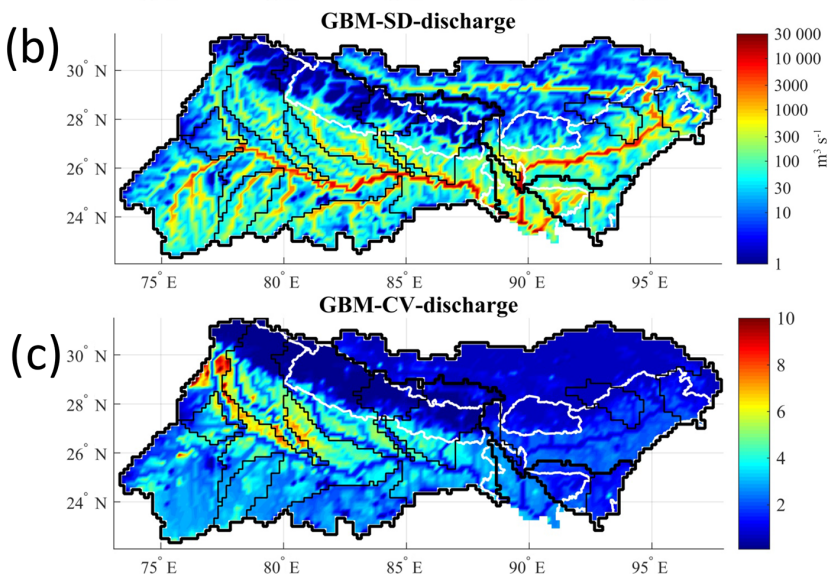

Figure 8. Maps of (a) the mean, (b) SD, and (c) CV of the simulated discharge for 1980-2001.

described in Sect. 2.2, the results of which will be discussed and analyzed in the next section. 
Table 1. BTOPMC sensitive parameters and their optimal parameter values with simulation performance.

\begin{tabular}{lrrrr}
\hline $\begin{array}{l}\text { Name of } \\
\text { parameter }\end{array}$ & $\begin{array}{r}\text { Drying } \\
\text { function } \\
\text { parameter }(\alpha)\end{array}$ & $\begin{array}{r}\text { Decay } \\
\text { factor } \\
(m)\end{array}$ & $\begin{array}{r}\text { Block average } \\
\text { Manning roughness } \\
\text { coefficient }\left(n_{0}\right)\end{array}$ \\
Unit & - & $\mathrm{m}$ & $\mathrm{s} \mathrm{m}^{-1 / 3}$ & \\
Value range & $-10-10$ & $0.01-0.1$ & $0.01-0.8$ & (Takeuchi et al., 2008) \\
\hline Basin & \multicolumn{5}{c}{ Best parameter values obtained from } & NSE (Nash-Sutcliffe \\
& parameter-sampling simulation & 0.009 & 0.80 \\
\hline Brahmaputra & -10 & 0.06 & 0.005 & 0.81 \\
Ganges & 10 & 0.3 & 0.1 & 0.91 \\
Meghna & 2 & 0.3 & & \\
\hline
\end{tabular}

\section{Results and discussion}

In this chapter, the results obtained by the case study described in Sect. 3 will be presented and discussed; namely, the geographical distribution of necessary storage over the basin was presented in Sect. 4.1, the effects of catchment area $A$ and its relation to statistical parameters of discharge $\mathrm{SD}$ and $\mathrm{CV}$ in Sect. 4.2, and their zoom-up relations in the selected 12 basins in the GBM basin in Sect. 4.3. Potential future study agenda are briefly discussed in Sect. 4.4.

\subsection{The geographical distribution of necessary storage over the basin}

Figures 9, 10 and 11 show the spatial distribution of necessary storage to smooth out the discharge variation over the Ganges-Brahmaputra-Meghna basin. Figures 9 and 10 assume the target release to be equal to long-term mean $Q_{\text {mean }}$ for both flood and drought management, while Fig. 11 assumes $3 Q_{\text {mean }}$ for flood management and $0.5 Q_{\text {mean }}$ for drought management. Figures $9,11 \mathrm{a}$ and $\mathrm{b}$ are in physical volume $\left(\mathrm{km}^{3}\right)$ and Fig. 10, 11c and $\mathrm{d}$ in residence time expression (months), the necessary storage divided by longterm mean $Q_{\text {mean }}$. All those figures directly imply the difficulty or ease of water resource management in a discharge variability aspect. Although the hydrological aspect is only a part of the actual difficulty of water resource management, its manageability in smoothing discharge variation is definitely an important factor. As Eq. (9) indicates, the distribution of necessary storage must be proportional in physical nature similar to the distribution of standard deviation (SD) of discharges in Fig. 8b, but its physical meaning in $\mathrm{km}^{3}$ is much more directly indicative of the size of dams, retardation ponds, tanks and the like than SD. Similarly, Eq. (10) indicates that the normalized necessary storage is proportional to the coefficient of variation $(\mathrm{CV})$ of Fig. 8c, but the mean residence time or renewal time in months is much more understandable and instructive than CV for water resource managers.
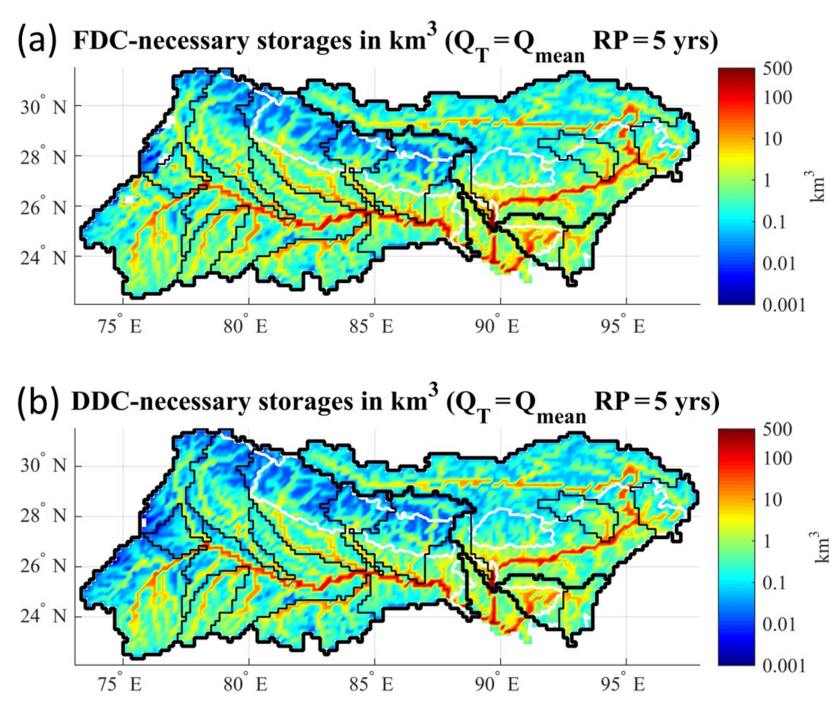

Figure 9. Necessary storages $\left(\mathrm{km}^{3}\right)$ for (a) flood and (b) drought management with target discharge $Q_{\mathrm{T}}=Q_{\text {mean }}$ of return period 5 years. The simulated discharge was for 1980-2001.

Comparing Figs. 9 and 10, or necessary storage in $\mathrm{km}^{3}$ and in months under target release $Q_{\mathrm{T}}=Q_{\text {mean }}$, the most obvious characteristics identifiable are the following.

1. The distributions of necessary storage for flood control and that for drought control; namely, the maps of Fig. 9a and $b$ in $\mathrm{km}^{3}$ and those of Fig. 10a and $b$ in months are similar. But Figs. 9 and 10 are very different. It means that necessary storages for flood and drought are rather similar, but the expressions in $\mathrm{km}^{3}$ and in months make them totally different. It is quite reasonable, as the target release is set equal to the long-term mean $Q_{\text {mean }}$, that the necessary storages for flood control and drought control are the same in a long run. The difference is only due to the short-term focus ( 1 year in this case), and such focus makes especially the necessary storage for drought smaller, which is clearly visible in Fig. 10. Note that Fig. 9a and $b$ seem to resemble each other more 


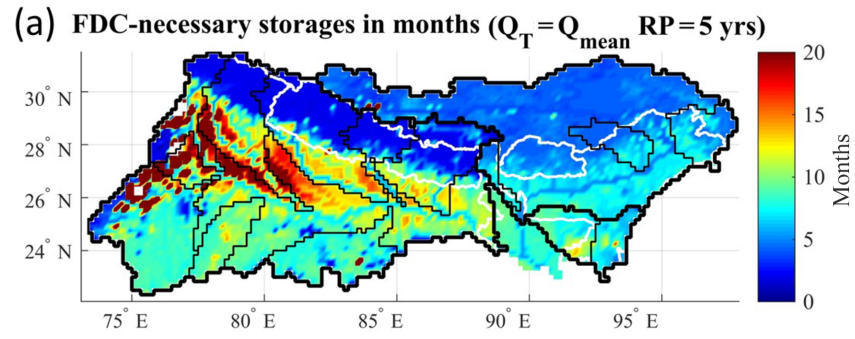

(b) DDC-necessary storages in months $\left(Q_{T}=Q_{\text {mean }} R P=5 \mathrm{yrs}\right)$

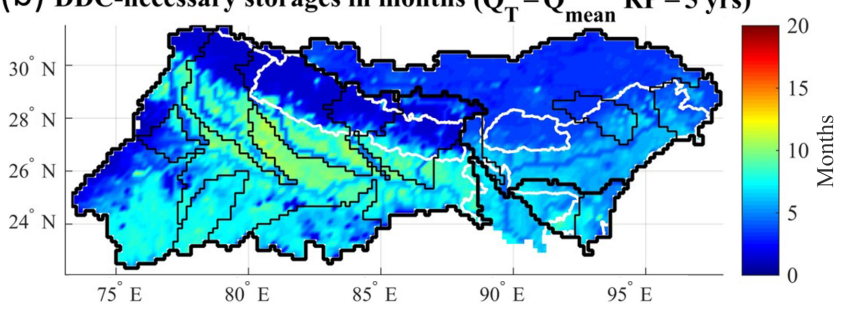

Figure 10. Necessary storage in months for (a) flood and (b) drought management with maintaining discharge $Q_{\mathrm{T}}=Q_{\text {mean }}$ of return period 5 years. The simulated discharge was for 1980 2001.

than Fig. 10a and b, which is simply because Fig. 9 is expressed in a logarithm to make small storage visible, while Fig. 10 is in real numbers.

2. The main difference between Figs. 9 and 10 is in the main stream. In terms of $\mathrm{km}^{3}$ in Fig. 9, along the main stream, the necessary storage increases as the catchment area increases towards downstream whereas in the upstream basins, the necessary storage is small and varies by location. But in terms of months in Fig. 10, along the main stream, months or the mean residence time decreases with catchment area. This is because the discharge increases in general with catchment area which increases the magnitude of variation and accordingly necessary storage to smooth it out. But in terms of residence time or the number of months of mean discharge, it decreases as the relative magnitude of variation to the mean discharge decreases with catchment area, similar to the specific flood peak discharge.

3. Both for flood and drought management, the necessary storage is small in the Himalayan high mountain areas where the discharge is stable with snow and glacier. On the contrary in north-eastern India approaching to the Himalayan areas in Fig. 10a, for flood, the very high months areas are concentrated, which reflects the semiarid climate with occasional floods, which makes flood control difficult. This is not visible for drought in Fig. 10b as multi-year fluctuation is not considered in this analysis. As stated in (1) above, the necessary storages for flood and drought control should become identical in a long run. The necessary storage for drought in this analysis therefore indicates the degree of difficulty of annual drought control. The difference between flood and drought is not very visible in $\mathrm{km}^{3}$ in Fig. 9 again partly because of its logarithmic expression.

Such characteristics correspond well to the SD and CV of Fig. $8 b$ and c, which are the proofs of Eqs. (9) and (10).

4. The geographical distribution of necessary storage in $\mathrm{km}^{3}$ in Fig. 9 and that of SD in Fig. 8b show a remarkable agreement, and this is also the case in months in Fig. 10 and $\mathrm{CV}$ in Fig. 8c.

5. Nearly identical to Fig. 10a of the necessary storage in months, large $\mathrm{CV}$ areas are scattering in north-eastern India in Fig. 8c. But for drought, it is not visible, as inter-annual smoothing is omitted.

Figure 11 is the same as Figs. 9 and 10 but with different target discharges, $3 Q_{\text {mean }}$ for flood and $0.5 Q_{\text {mean }}$ for drought management. Figure $11 \mathrm{a}$ and $\mathrm{b}$ are in $\mathrm{km}^{3}$, and $\mathrm{c}$ and $\mathrm{d}$ in months.

6. The most remarkable feature of Fig. 11 is that there are many blank areas in the maps, which means that no storage is necessary as the natural discharge variation itself is within the $\left(0.5 Q_{\text {mean }}, 3 Q_{\text {mean }}\right)$ range as long as 5-year return period discharges are concerned.

7. The blank areas of Fig. 11 coincide well with the blue areas (low necessary storage areas) of Figs. 9 and 10, both for flood and drought. They are mostly headwater areas, especially in the high Himalayan mountain areas with snow. In case of drought, the blank areas extend to the areas of low precipitation in the Western Gages as shown in Fig. 3b. The reason is simply low discharge variation in those areas, which corresponds to relatively low CV in Fig. 8c. On the other hand, the areas with high CV are not blank, and especially for flood, the high red areas of Fig. 8c correspond to the red areas of Fig. 11c.

\subsection{Comparison of necessary storage with the catchment area and SD and $\mathrm{CV}$ of discharge in a scatter diagram}

Following the findings of spatial resemblance of geographical distributions of necessary storage and SD and CV of discharge, this section further looks into their relation by basins and catchment area using scatter diagrams. This is an initial trial to see whether any extra information may be derivable from necessary storage signature that is different from SD and CV on hydrological characteristics of basins. Figure 12 shows the relation between necessary storage $V_{\mathrm{km}^{3}}\left(\mathrm{~km}^{3}\right)$ and catchment area $A\left(\mathrm{~km}^{2}\right)$, and Fig. 13 the same on normalized necessary storage $V_{\text {month }}$ (months). Figure 14 shows the relation between $V_{\text {month }}$ and $\mathrm{SD}\left(\mathrm{m}^{3} \mathrm{~s}^{-1}\right)$ of daily discharge, 

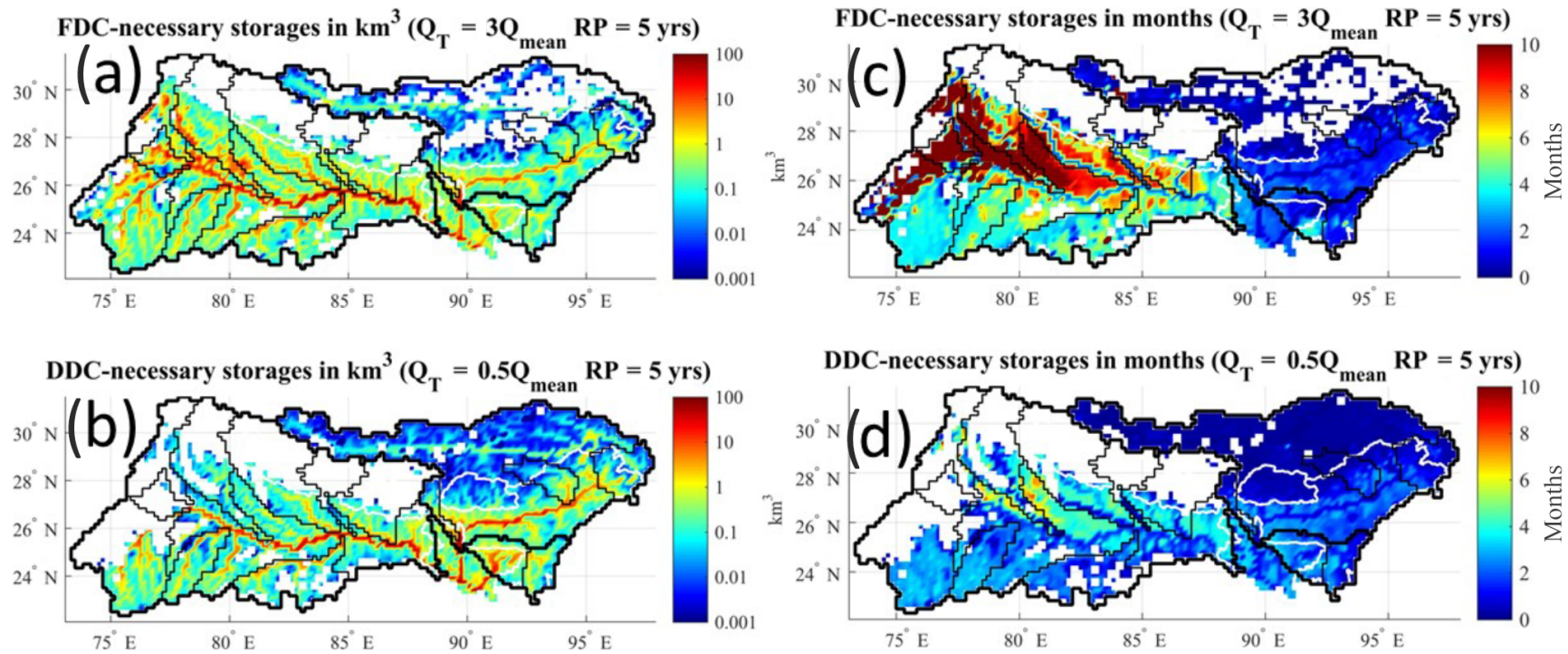

Figure 11. Necessary storages $(\mathbf{a}, \mathbf{b})$ in $\mathrm{km}^{3}$ and $(\mathbf{c}, \mathbf{d})$ in months $(\mathbf{a}, \mathbf{c})$ for flood and $(\mathbf{b}, \mathbf{d})$ for drought management to maintain $Q_{\mathrm{T}}=3 Q_{\mathrm{mean}}$ during flood and $Q_{\mathrm{T}}=0.5 Q_{\text {mean }}$ during drought of a return period of 5 years. The simulated discharge was for 1980-2001.

(a)

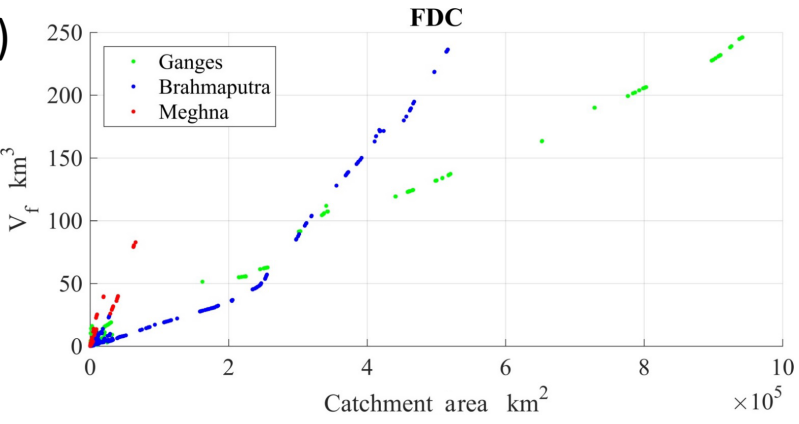

(b)

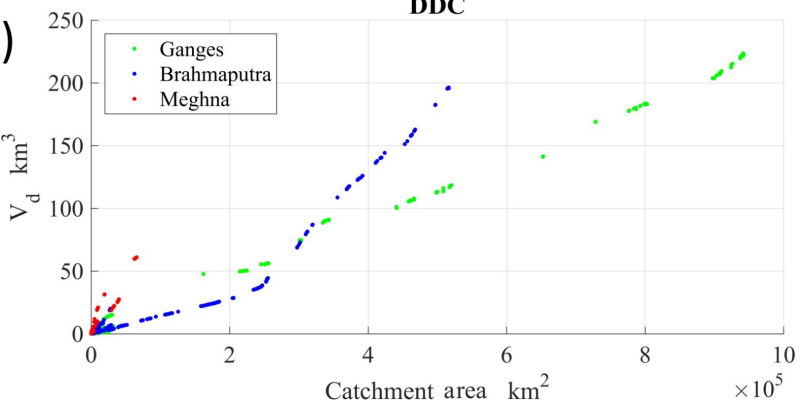

Figure 12. Relation between necessary storage $\left(\mathrm{km}^{3}\right)$ and catchment area $\left(\mathrm{km}^{2}\right)$ for (a) flood and (b) drought management in the three basins of the GBM basin.

and Fig. 15 the same with CV. Each dot corresponds to each 10 arcmin grid cell in the basin, and there are altogether 5263 dots (Ganges 3220, Brahmaputra 1812 and Meghna 231) in Figs. 12-15.

There are two common observations to be explained.

1. In all of Figs. 12-15, the dots are discontinuous. In Figs. 12 and 13, the reason is because the catchment (a)

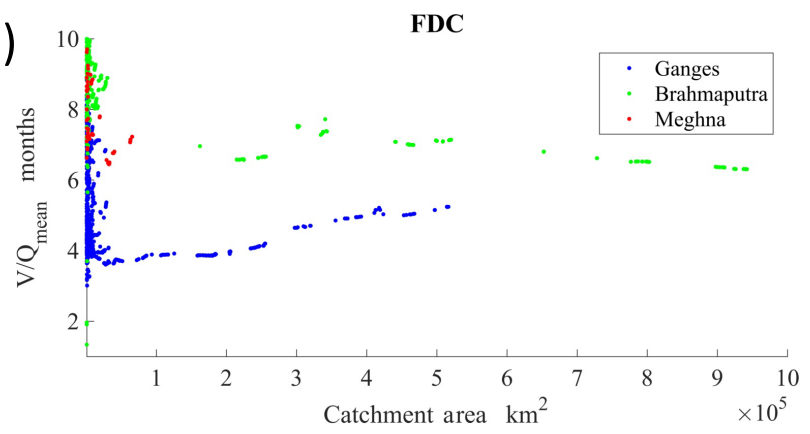

(b)

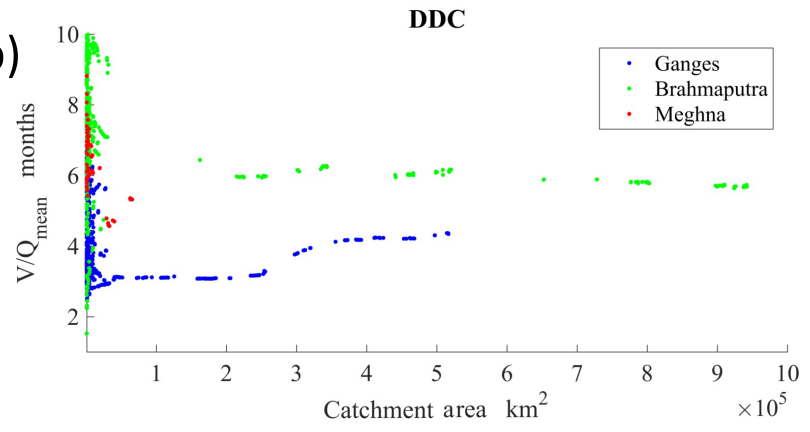

Figure 13. Relation between necessary storage in months and catchment area $\left(\mathrm{km}^{2}\right)$ at all grid points of the basin with maintaining discharge $Q_{\mathrm{T}}=Q_{\text {mean }}$ for (a) flood and (b) drought management with a 5-year return period.

area and discharge increase discontinuously where tributaries converge to the main river merging sub-basins of some size and flow. In Fig. 14, it is because the SD increases following the discontinuous increase in the catchment area. In the case of Fig. 15, it is simply because each sub-basin has a different $\mathrm{CV}$. 

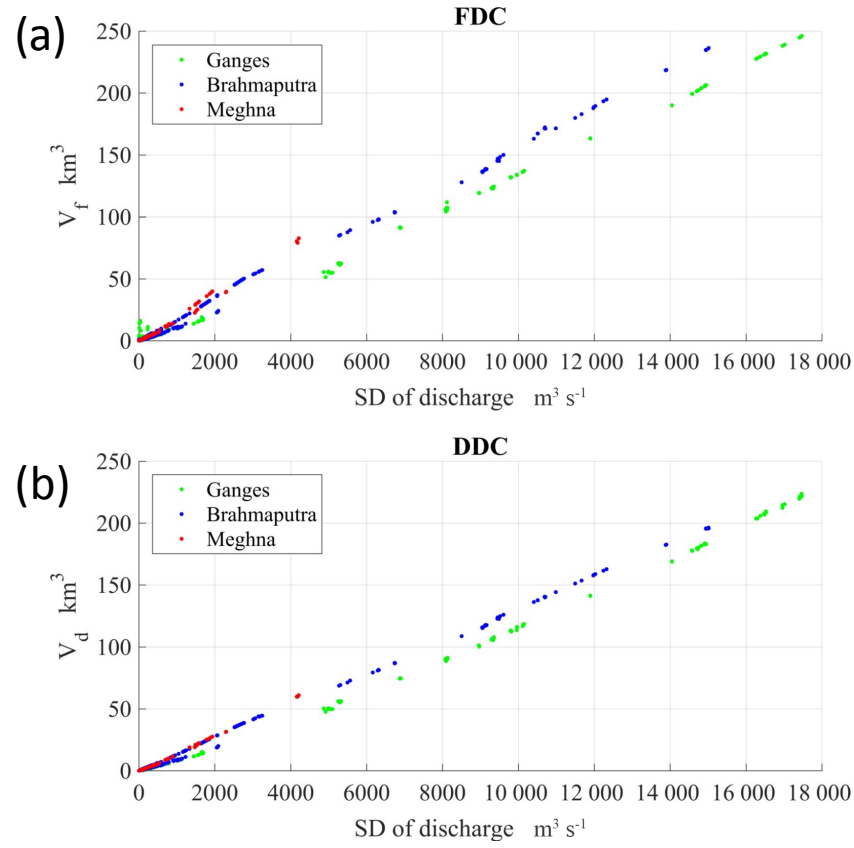

Figure 14. Relation between necessary storage $\left(\mathrm{km}^{3}\right)$ and SD $\left(\mathrm{m}^{3} \mathrm{~s}^{-1}\right)$ of discharge at all grid points in the GBM basin for (a) flood and (b) drought management.

2. The other common observation is that all figures (a) for flood and (b) for drought are quite similar, which is for the same reason mentioned in List 1 in Sect. 4.1. At the same time, their levels are considerably different; that is, the necessary storage for drought control is smaller than that for flood control. This is because in this paper the necessary storage is calculated for short-term intra-annual control ( $m \leq 365$ days). In general, flood is huge within a year and there is no need to consider interannual flood control space to keep the long-term mean discharge, but in the case of drought, intra-annual control of drought may not require much storage to replenish, but inter-annual drought (sometimes it extends over a decade) becomes predominantly large. By limiting the consideration into annual smoothing in this paper, the necessary storage for drought is considerably less than that for flood control in the GBM basin, where there is a distinct wet season and a dry season. The difference between the necessary storage for flood and drought would indicate the inter-annual dependency of drought, which would be an interesting subject for future study.

The Fig. $12 V_{\mathrm{km}^{3}}-A$ relation indicates how necessary storage increases with catchment area. (1) Necessary storage $V_{\mathrm{km}^{3}}$ increases generally in proportion to catchment area $A$ as discharge variability increases with catchment area through an increase in discharge volume. But (2) the slope is different in each basin, which would reflect the overall hydrological variability of sub-basins merging into the main stream. The relative differences of slopes of three sub-basins of the GBM would be explained as follows.

3. The Meghna has a larger slope of necessary storage against catchment area than the other basins, both for flood and drought, which must reflect large specific discharge with large variability of the Meghna.

4. The Brahmaputra has a distinct slope change from low to high at around $250000 \mathrm{~km}^{2}$ point which corresponds to the outlet from the Tibet. As Fig. 3b indicates, in upstream, precipitation is low with snow and glacier being dominant and in downstream, precipitation is high, making specific discharge and thus variability similar to the Meghna, which makes the slope of necessary storage markedly changes from low to high.

5. The Ganges has a rather low stable slope in the entire river length. This reflects rather stable river flow as a collection of many dry sub-basins in the east, mildly humid southern basins and ample but stable snow-fed discharge in high mountains. The slope is as low as the Tibetan part of the Brahmaputra.

The Figure $13 V_{\text {month }}-A$ relation has a distinct feature showing the following. (1) In the areas with a smaller catchment $A$ of less than a few $10000 \mathrm{~km}^{2}$, the normalized necessary storage $V_{\text {month }}$ varies widely, but (2) as the catchment area becomes large, it converges to a stable line unique to each basin. (3) Those lines are not necessarily horizontal but either a decreasing or an ascending trend with catchment area. Such characteristics do reflect the characteristics of the basins and would be explained as follows.

6. Large scatter at the origin of catchment area must reflect many different grid cells having many different hydrological conditions including land use, land cover and other geographical and geological variability. Such detailed relation should be examined based on detailed land cover information, which requires much finer resolution maps than Figs. 2 and 3, which is beyond the scope of this first step analysis and left for future study.

7. How large a basin should be to have a converging line or if there is no convergence in general would be a very interesting question on scale effect relating to hydrological heterogeneity of a basin. In Fig. 13 it seems a few $10000 \mathrm{~km}^{2}$ and no details can be said without more elaborate examination in many different basins in the world. In the next Sect. 4.3, a further look of the GBM basin in sub-basin levels are presented.

8. The levels of converging lines at the river mouth seem roughly as follows.

For flood, $V_{\text {month }}=6.2$ months for the Ganges and 5.4 months for the Brahmaputra. 
For drought, $V_{\text {month }}=5.5$ months for the Ganges and 4.5 months for the Brahmaputra.

The Meghna case seems to be somewhere between the two, but is too short to observe the convergence.

Figures 13a for flood and $\mathrm{b}$ for drought are roughly in parallel, although the levels are different. The difference in levels (namely, 6.2-5.5 $=0.7$ months for the Ganges and 5.4-4.5 $=0.9$ months for the Brahmaputra at the river mouth) reflects their difference in persistence characteristics of discharge variability. The Brahmaputra has more inter-annual variability for drought than the Ganges at the mouth, and limiting smoothing length by a year results in higher difference in necessary storage for flood and drought. Note the discussions in List 13 in Sect. 4.2 on the difference between $V_{\text {month }}$ for flood and drought.

9. On the slopes of the converging lines, the Ganges has a descending slope and the Brahmaputra an ascending slope. Namely, in the Ganges, it is $\frac{\mathrm{d} V_{\text {month }}}{\mathrm{d} A}<0$, and in the Brahmaputra, it is $\frac{\mathrm{d} V_{\text {month }}}{\mathrm{d} A}>0$. This should be related to their basin transition from upstream to downstream. In the Ganges, the river flows from the western Ganges, needing more storage (in months), under a semi-arid climate to the eastern Ganges, needing less storage, under a more humid and stable climate (see Fig. 10). In contrast, in the Brahmaputra, it flows from the northern Brahmaputra, with a snow-affected region needing less storage, to the southern Brahmaputra with high precipitation and without a snow stabilizer.

Figure $14 V_{\mathrm{km}^{3}}-\mathrm{SD}$ and Fig. $15 V_{\text {month }}-\mathrm{CV}$ are the examination of indicated formulas of Eqs. (9) and (10) based on Eq. (8), the finding of Hurst (1951). From them the following are observable.

10. Figure 14 shows a remarkable proportionality between $V_{\mathrm{km}^{3}}$ and SD as indicated by Eq. (9) of Hurst (1951). The relation seems, by visual judgment, roughly the following:

$$
\begin{aligned}
& V_{\mathrm{f}}\left(\mathrm{km}^{3}\right) \approx(1 / 70) \mathrm{SD}\left(\mathrm{m}^{3} \mathrm{~s}^{-1}\right), \\
& V_{\mathrm{d}}\left(\mathrm{km}^{3}\right) \approx(1 / 80) \mathrm{SD}\left(\mathrm{m}^{3} \mathrm{~s}^{-1}\right) .
\end{aligned}
$$

Such relations, however, would be valid only along the large main streams of the GBM basin because most points visible in Fig. 14 are along the large main streams having large discharge with a large SD. Most of the points in the figure are concentrated near the origin, with a small SD and a small $V$ to which those formulas do not apply.

11. The slope of the $V-\mathrm{SD}$ relation seems a bit larger in the Meghna, then in the Brahmaputra, and the smallest in the Ganges. This relation is similar in the Fig. 12
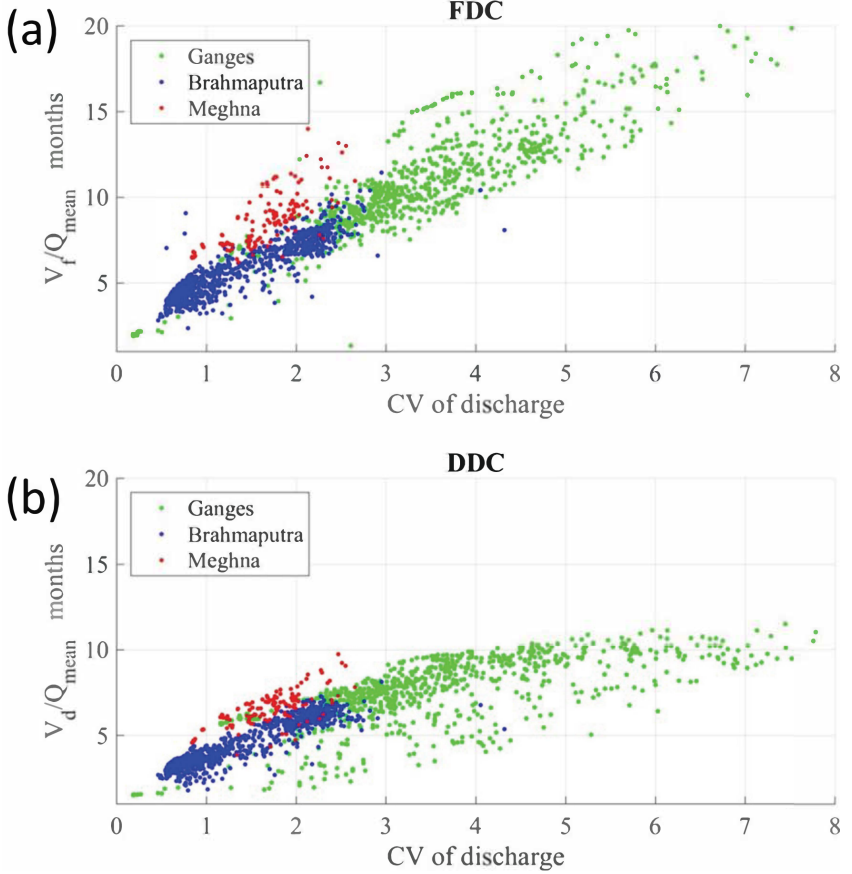

Figure 15. Relation between necessary storage in months and CV of daily discharge of a 5-year return period for (a) flood and (b) drought management at all grid points of the GBM basin.

$A-V$ relation although the shapes are different. This is because the relation between SD and catchment area $A$ is roughly proportional although not linear with a constant coefficient. The coefficient of $A-V$ changes distinctly where the Brahmaputra leaves Tibet, as indicated by Fig. 12 but not clearly visible in Fig. 14. This is because the SD- $V$ relation does not change by discharge amount, as Eq. (9) indicates.

12. The Figure $15 V_{\text {month }}-\mathrm{CV}$ relation shows widely scattered points distinctly different from the Fig. $14 V_{\mathrm{km}^{3}}$ $\mathrm{SD}$ relation. This is because the variation of $\mathrm{CV}$ is independent of the magnitude of discharge and the size of the basin, while SD is roughly proportional to the magnitude of discharge and accordingly the size of the basin. As a result, the points representing smaller head basins are more visible in Fig. 15 and their hydrological heterogeneity is more prominently reflected in the location within the scatter. Note that in small head basins, hydrological heterogeneity more directly influences discharge variability than in large basins at their outlets. This heterogeneity will be more focused in the next Sect. 4.3.

13. Figure 15 indicates the relation of Eq. (10) and the coefficients of average linear relations for flood and drought seem by "crude" visual judgement as follows: 
$V_{\text {month-f }} \approx 5 \mathrm{CV}$ for the Meghna, $3.3 \mathrm{CV}$ for the

Ganges and 3.3 CV for the Brahmaputra;

$V_{\text {month-d }} \approx 3.5 \mathrm{CV}$ for the Meghna, $2 \mathrm{CV}$ for the

Ganges and 2.5 CV for the Brahmaputra.

The relative difference in coefficients would indicate the difficulty factor or the disadvantageous factor of water resource management with respect to necessary storage. A higher coefficient implies that with a given level of discharge variability in $\mathrm{CV}$, one basin needs more storage to smooth out the variation than another basin. It should be related to the persistence structure of a hydrological process which is influenced by basin heterogeneity such as geophysical and geographical conditions including climatology, land cover and land use. Besides, the relative departure of a point from the average relation would also indicate the relative ease or difficulty of discharge control within the basin. Although we have no answer yet on what hydrological conditions control such a factor, it is a very interesting area of hydrological sciences to be studied in the future.

\subsection{Effect of heterogeneity of basin hydrology on necessary storage}

As found in the analyses of Sect. 4.1 and 4.2, the slope of the linear relationship between necessary storage $V$ and $A$, SD and $\mathrm{CV}$, and the scatter of deviations of $V$ from its average relationship vary by basin depending on its characteristics of hydrological conditions such as elevation, topography, geology, precipitation and land cover including vegetation, soil and land use of the basin, some of which are shown in Figs. 2 and 3. Such variation is the source of extra information on hydrological heterogeneity of a basin that necessary storage has but traditional SD and CV do not. This section therefore looks into details of slopes and scatter of the $V_{\text {month }}-A$ relation in Fig. 13 and $V_{\text {month }}-\mathrm{CV}$ in Fig. 15 by their zoom-ups, Figs. 16 and 17, respectively, in selected 12 sub-basins indicated in the map in the center. They are selected to cover different areas of hydrological conditions.

Note that the zoom-ups of the $V-A$ relation in Fig. 12 and $V-\mathrm{SD}$ in Fig. 14 were not examined as they are basically linear, as Hurst (1951) showed in Eq. (9), and there is strong linearity of catchment area $A$ with SD.

Figure 16 is the zoom-up of Fig. 13 on the $A-V_{\text {month }}$ relation of each basin. The following are observable.

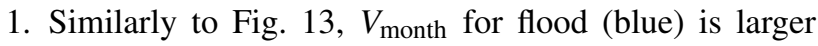
than that for drought (red) in general, although they are mixed near the origin (head basins). The reasons were explained in Lists 1 in Sect. 4.1 and Lines 6-9 in Sect. $4.2=$.
2. There is a wide scatter of $V_{\text {month }}$ near the origin which eventually converges to near-horizontal lines around 6 months as the catchment becomes larger. The converging lines are not necessarily just one from the beginning, but a few representing branch rivers before they merge into the main stream of sub-basins. The total shape may be roughly described as a horizontally laid bell shape which is similar to Fig. 13 and explained in Lists 6-9 in Sect. 4.2 .

3. The upper six basins of the Ganges, Yamuna, Ganga, Ghanhara, Gandak and Kosi and a western Brahmaputra basin, Teesta, have upward converging lines. These basins originate from the Himalayan mountains, receiving ample snowmelt water and flowing down to the south. Their form is considerably distorted from Fig. 13, with wide scattering $V_{\text {month }}$ near the origin, followed by very low $V_{\text {month }}$ especially for drought and a gradual increase with the catchment area. A large scatter is due to wide heterogeneity of the basin due to a large catchment and varieties of climatic conditions in the basin. Small $V_{\text {month }}$ near the origin may be attributed to a dominant snowmelt influence with little variability, as the dark blue areas in Fig. 8b (SD) and c (CV) show. But $V_{\text {month }}$ gradually increases as the main river flows down to low land in the south, receiving ample rainfall with high variability as shown in Fig. 8.

4. Two basins, Subansiri and Lohit in the Brahmaputra, are small and less heterogeneous (rather uniform conditions) with snowmelt influence and quickly converge to the average.

5. The basins along the southern edges of the Ganges and the Meghna to the southern slopes of the Brahmaputra, Chambal, Betwa, Son, and Barak have a horizontally laid bell shape similar to Fig. 13. This may be because they receive no snowfall and the river flow increases rather proportionally with catchment area, and so does necessary storage that results in a quick convergence to a basin average although the headwater basins vary considerably in $V_{\text {month }}$. The Chambal is unique in that the $V_{\text {month }}$ for flood and drought are the same in the main stream over $5 \times 10^{5} \mathrm{~km}^{2}$ and the converging line is slightly downward. This may reflect large variability upstream by the influence of semi-arid climate in the west and rather stable humid climate in the east, as Fig. 3b indicates. Similarity for flood and drought is due to similarity of their inter-annual variability, which needs further study in the future.

6. The average catchment area (scale) where the $A-V_{\text {month }}$ relation converges to a near-horizontal line seems a few $10000 \mathrm{~km}^{2}$ in most sub-basins. The hydrological mechanism to determine such a critical scale would be an interesting subject of further study, as discussed in List 13 in Sect. 4.2. 


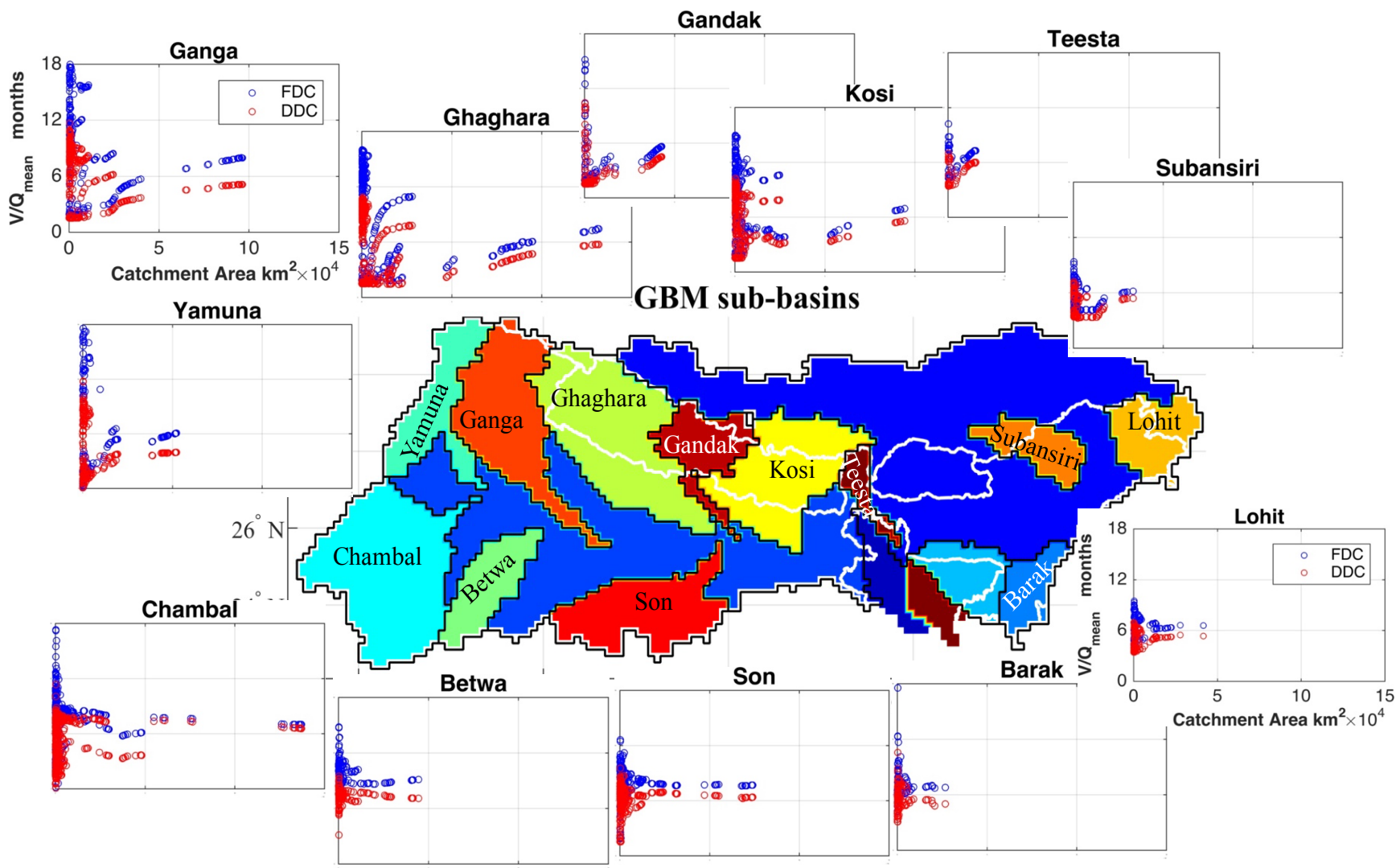

Figure 16. Zoom-ups of Fig. 13 at the selected 12 sub-basins of the GBM, i.e., relations between necessary storage in months for flood (blue) and drought (red) management and catchment area $\left(\mathrm{km}^{2}\right)$ at all grid points of GBM sub-basins as indicated in the center with maintaining discharge $Q_{\mathrm{T}}=Q_{\text {mean }}$ during discharge with a 5-year return period. The simulated discharge was for 1980-2001.

Figure $17 \mathrm{a}$ is the zoom-up of Fig. 15 on the $V_{\text {month }}-$ $\mathrm{CV}$ relation. Here diagrams of the numerical summary of Figs. 2 and 3 are also attached for easy reference, i.e., elevation $(H)$, precipitation $(P)$ and land cover $(L)$ distributions of the basin. Figure 17b shows the legend of the summary diagrams. Figure 17a indicates the following.

7. Again, the normalized necessary storage is larger for flood than for drought in general, with considerable mixture in a wide range of CVs. The wide range is due to small catchments (head water basins) scattered in CVs.

8. The $H-P-L$ distribution diagrams indicate, on elevation $(H)$, over $2000 \mathrm{~m}$ area is more than $30 \%$ in sub-basins in the northern Ganges to the Brahmaputra basins, including Gandak, Kosi, Teesta, Subansiri and Lohit. The flat or low land prevails in the subbasins in the western to the southern Ganges to southern Meghna, Ganga, Yamuna, Chambal, Betwa, Son and Barak. On precipitation $(P)$, dry basins with less than 500-1000 mm are dominant in Ganga, Yamuna, Chambal and Betwa; on the other hand, basins with over $2000 \mathrm{~mm} \mathrm{yr}^{-1}$ prevails in in the Meghna to the Brahma- putra, Barak, Rohit, and Subansiri. On land cover $(L)$, the salient feature is that crop land prevails in Ganga, Yamuna, Chambal, Betwa and Son, and that forests prevail in Barak, Lohit, Subansiri and Teesta.

9. Six sub-basins in the western to the northern Ganges, from the Chambal to the Kosi, have wide ranges of $\mathrm{CV}, 0-6$ or $0-8$. They are relatively large sub-basins covering heterogeneous regions. On the other hand, the other six located in the Brahmaputra and the southern edges of the Ganges and the Meghna show a rather concentrated cluster of points or a narrow range of CV. This would be because sub-basins are smaller, compared with the upper six and although the $H-P-L$ variability seems large as the summary diagram indicates, discharge variability is kept small in CV. The reasons may be in the dominant effects of hydrology, partly explained in the following (10) and (11).

10. The scatter is especially large in the Yamuna and the Ganga followed by the Chambal and the Ghaghara which, as Fig. 3a indicates, except the Chambal, originate from the high Himalayan Mountains and flow down to the highland plateau and eventually to the low- 


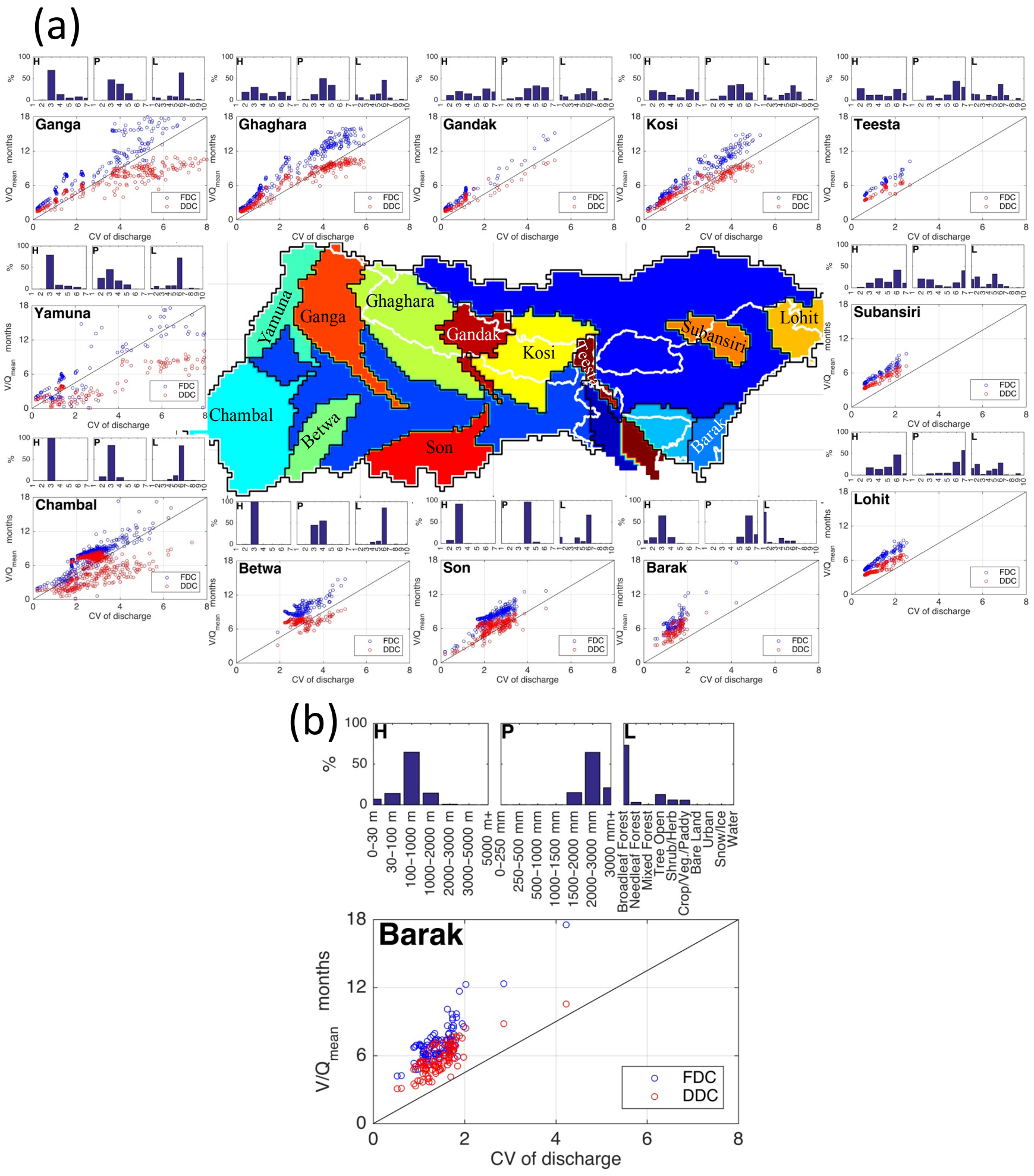

Figure 17. (a) Zoom-ups of Fig. 15 at the selected 12 sub-basins of the GBM with a summary of elevation $(H)$, precipitation $(P)$ and land cover $(L)$ distribution, i.e., the relation between necessary storage in months and CV of daily discharge for flood (blue) and drought (red) management at all grid points of sub-basins as indicated in the center with maintaining discharge $Q_{\mathrm{T}}=Q_{\text {mean }}$ during a 5-year return period. The simulated discharge was for 1980-2001. (b) Legend of diagrams in (a). 
land plain. In the plateau and the plain of the Chambal, Yamuna and Ganga, it is rather dry or semi-arid climate, and, as the summary diagrams of Figs. 2 and 17a show, it is used for extended cropland, which makes discharge variability high through evapotranspiration. Such heterogeneity in land use contributes to the large scatter of $V_{\text {month }}$.

11. On the other hand, the scatter is especially small in three Brahmaputra sub-basins, the Teesta, the Subansiri and the Lohit, which start from a strong snowmelt effect in the high Himalayan mountains and flow down to one of the thickest forest regions in the world, where discharge variability is small.

12. In relation to Eq. (10), the average line of the points (corresponding to each grid cell of the sub-basin) is expected to pass the origin. It is the case in Fig. 15 but not in Fig. 17a. The height of each point ( $V_{\text {month }}$ signature) still indicates the relative difficulty of discharge control among the points having the same $\mathrm{CV}$, but the slope of average lines of a basin discussed in List 13 in Sect. 4.2 is not clearly visible in Fig. 17a. The reason for or the implication of Eq. (10) would be another interesting subject for further study.

\subsection{Some other thoughts on future investigation}

Although a number of unknown areas are mentioned for further analyses in discussions above, some more important areas are briefly described below.

\subsubsection{Potential use of spatially distributed necessary storage information for water resource management}

In this paper, necessary storage is proposed as a signature of hydrological variability in time. Its advantage over other statistical indicators is obvious as it is in human terms and has a direct implication for the ease and difficulty of water resource management. But what about its spatially distributed information? Does this have any use to water resource managers? It is a difficult question and the next step of this analysis. But some potential areas of investigation may be indicated. One would be an implication of spatial differences of necessary storage in months in independent sub-basins that may have a potential benefit of water transfer. It may be beneficial to transfer water stored in an area with a shorter mean refilling time (months) to another area with a longer refilling time (months). Another would be the relation to land use for agriculture; that is, the area with smaller necessary storage may indicate a relative advantage for water demanding vegetation. Gao et al. (2014) looked into the terrestrial ecosystem's root zone moisture capacity at the catchment scale and found it equivalent to the necessary storage for a 10-40-year drought. If the necessary storage is small, it would need smaller root zone capacity, and larger if not, which may indicate some suited agricultural or forestry land use. The other potential area would be the investigation of the impact on downstream when a reservoir was built or to be operated. That would necessitate study on longitudinal changes in necessary storage along river lines, which may indicate an advantageous site of dam construction or operation in a hydrological sense. Reservoir construction sites or reservoir operation which has less impact on downstream areas would be desirable from an environmental point of view.

\subsubsection{Scale effect of normalized necessary storage in months}

Another potential area of further study is the scale effect of normalized necessary storage in months, i.e., the $V_{\text {month }}-A$ relation. Figure 13 is its large basin behavior and Fig. 16 is its zoom-up in the selected 12 sub-basins. All figures indicate that in a few $10000 \mathrm{~km}^{2}$ catchment area, the normalized necessary storage becomes stable unless different large branch rivers join with different characteristic months. This may have a conceptual analogy similar to the discussion of the representative elementary area (REA) concept (Wood et al., 1988) based on the finding that the variability of hydrological processes becomes low once the area becomes larger than around $1 \mathrm{~km}^{2}$. Hydrological variability in the storage domain and its governing mechanism would deserve further attention.

\section{Conclusions}

This paper introduced necessary storage to smooth out discharge variation to meet a given target as a signature of discharge variability in time and presented it in a geographical distribution to analyze its relation to hydrological, including geophysical and geographical, heterogeneity of a basin. The signature of necessary storage has a distinct advantage over other indicators of variability such as SD and CV, as it is expressed in concrete human terms and integrated with persistence characteristics of variability. This paper showed that the scatter pattern of departure of signature from its average relationship with parameters such as $A, \mathrm{SD}$ and $\mathrm{CV}$ indicated characteristics of the hydrological heterogeneity of a basin. Analysis of departure by extending it to global maps would lead to new scientific understanding of hydrological heterogeneity.

The case presented here was with the target to maintain long-term mean discharge $Q_{\text {mean }}$ in a 5-year return period. But such a target level can be chosen arbitrarily such as $3 Q_{\text {mean }}$ for flood and $0.5 Q_{\text {mean }}$ for drought (Fig. 11) and in different return periods or rates of failure. The signature was calculated from intensity-duration-frequency curves of daily discharge called flood duration curves (FDCs) and drought duration curves (DDCs) to ease the calculation of 
necessary storage at all grid points of a basin and plotted to geographical maps for the Ganges-Brahmaputra-Meghna (GBM) basin. In addition to analyses of the basin as a whole, 12 selected sub-basins were focused and tried to relate the necessary storage signature to their hydrological characteristics. Although this paper showed only the first trial of the analysis of signature, we believe that the potential use of it and the validity of the methodology were demonstrated and that the following would be concluded.

The necessary storage serves as a signature of discharge variability in time and its geographical distribution provides a means of analyzing hydrological heterogeneity.

The necessary storage signature has a distinct advantage to measure hydrological variability over other conventional statistical indicators such as SD and CV, as it has human terms "reservoir storage in $\mathrm{km}^{3}$ or mean refilling time in months" which directly indicates the ease and difficulty of flood and drought management. In addition, it is an integrated indicator including the effects of persistence characteristics of variability which SD and CV do not have.

Necessary storage is a signature that has the potential to show something extra to statistical variability indicators such as $\mathrm{SD}$ and $\mathrm{CV}$. The analyses of the scatter pattern of departures from the normal relations of $V-A, V-\mathrm{SD}$ and $V-\mathrm{CV}$ would lead hydrological sciences to new insights into the geographical distribution of hydrological heterogeneity.

Calculating necessary storage by intensity-durationfrequency curves, FDC and DDC, is a practical and convenient way that is beneficial for extending the study to the globe.

The signature in $\mathrm{km}^{3}$ generally becomes larger with increase in catchment area so that the major river routes emerge out as blood vessels with larger values than the surroundings. The signature in months, normalized by the local longterm mean, however, converges to smaller values than the surrounding points representing smaller catchments as river discharge is stabilized as a catchment becomes larger.

In the headwater areas where river routes do not distinctly emerge as catchments are small and concentration effect is not dominant, the signature both in $\mathrm{km}^{3}$ and months reflects much on hydro-meteorological and other geophysical and geographical heterogeneity of a catchment. The initial observations of departures from the average relationship with $A$ and CV seem to indicate that necessary storage both for flood and drought management is small in snow-and-glacieraffected areas and large in lower plains under both dry and humid climate reflecting their degree of variability. In addition, necessary storage is small in thick forests and large in heavy cropland.

In main streams, on the other hand, the variation converges to the average basin characteristics towards the river mouth but whether the converging trend is descending, ascending or flat depends on basin characteristics. Such unique scale effects in different basins would be an important area of investigation to be related to hydrological heterogeneity of a basin. It seems to have some similarity to the concept of representative elementary area (REA) introduced by Eric Wood and his colleagues (Wood et al., 1988) on scale effects on spatial heterogeneity of hydrological processes.

A creation of global maps of necessary storage would be effective for analyses of such hydrological heterogeneity in the storage domain and a useful challenge for assessment of the current state of water resources and climate change impact on water resources.

Data availability. The meteorological data have been collected from the WATCH forcing dataset (WFD) which is publicly available from the website http://www.eu-watch.org/, https://doi.org/10.1175/2011JHM1369.1.

Hydrological data have been collected from Hydrology Division of Bangladesh Water Development Board (BWDB) and are not publicly available and not free of charge.

Competing interests. The authors declare that they have no conflict of interest.

Special issue statement. This article is part of the special issue "Observations and modeling of land surface water and energy exchanges across scales: special issue in Honor of Eric F. Wood". It is a result of the Symposium in Honor of Eric F. Wood: Observations and Modeling across Scales, Princeton, New Jersey, USA, 2-3 June 2016.

Acknowledgements. We express our deepest gratitude to Eric Wood, Princeton University, for giving us an inspiring opportunity to present the results of this research in his honorary symposium, and to Murugesu Sivapalan, University of Illinois, for his kind encouragement and invaluable suggestions throughout the presentation and publication processes. Our gratitude extends also to the anonymous reviewers who provided many valuable comments.

Edited by: Murugesu Sivapalan

Reviewed by: five anonymous referees

\section{References}

Ao, T. Q., Ishidaira, H., and Takeuchi, K.: Study of distributed runoff simulation model based on block type TOPMODEL and Muskingum-Cunge method, Ann. J. Hydraul. Eng., JSCE, 43, 712, 1999.

Ao, T., Yoshitani, J., Takeuchi, K., Fukami, H., Matsuura, T., and Ishidaira, H.: Effects of sub-basin scale on runoff simulation in distributed model: BTOPMC, IAHS Publ., 282, 227-233, 2003.

Ao, T., Ishidaira, H., Takeuchi, K., Kiem, A., Yoshitani, J., Fukami, K., and Magome, J.: Relating BTOPMC model parameters to physical features of MOPEX basins, J. Hydrol., 320, 84-102, 2006. 
AQUASTAT: Ganges-Brahmaputra-Meghna river basin, Irrigation in Southern and Eastern Asia in figures - AQUASTAT Survey - 2011, http://www.fao.org/nr/water/aquastat/basins/gbm/index. stm (last access: 1 September 2017), 2011.

Beven, K. J. and Kirkby, M. J.: A physically based, variable contributing area model of hydrology, Hydrological ScienceBulletin, 24, 43-69, 1979.

Blöschl, G., Sivapalan, M., Wagener, T., Viglione, A., and Savenije, H. (Eds.): Runoff Prediction in Ungauged Basins, in: Runoff prediction in ungauged basins: Synthesis across processes, places and scales, Cambridge University Press, Cambridge, https://doi.org/10.1017/CBO9781139235761, 2013.

Creager, W. P., Justin, J. D., and Hinds, J.: Engineering for Dams, vol. 1, John Wiley, NY, USA, 1945.

Cunge, J. A.: On the subject of a flood propagation computation method (Muskingum method), J. Hydraul. Res., 7., 205-230, 1969.

Feller, W.: The asymptotic distribution of the range of sums of independent random variables, Ann. Math. Stat., 22, 427-432, 1951.

Gao, H., Hrachowitz, M., Schymanski, S. J., Fenicia, F., Sriwongsitanon, N., and Savenije, H. H. G.: Climate controls how ecosystems size the root zone storage capacity at catchment scale, Geophys. Res. Lett., AGU, 7916-7923, https://doi.org/10.1002/2014GL061668, 2014.

Gusyev, M., Gädeke, A., Cullmann, J., Magome, J., Sugiura, A., Sawano, H., and Takeuchi, K.: Connecting globaland local-scale flood risk assessment: a case study of the Rhine River basin flood hazard, J. Flood Risk Manage., https://doi.org/10.1111/jfr3.12243, in press, 2016.

Hanasaki, N., Kanae, S., Oki, T., Masuda, K., Motoya, K., Shirakawa, N., Shen, Y., and Tanaka, K.: An integrated model for the assessment of global water resources - Part 1: Model description and input meteorological forcing, Hydrol. Earth Syst. Sci., 12, 1007-1025, https://doi.org/10.5194/hess-12-1007-2008, 2008.

Hapuarachchi, H. A. P., Kuniyoshi Takeuchi, K., Zhou, M., Kiem, A. S., Georgievski, M., Magome, J., and Ishidaira, H.: Investigation of the Mekong River basin hydrology for 1980-2000 using the YHyM, Hydrolog. Process., 22, 1246-1256, 2008.

Hirabayashi, Y., Mahendran, R., Koirala, S., Konoshima, L., Yamazaki, D., Watanabe, S., Kim , H., and Kanae, S.: Global flood risk under climate change, Nature Climate Change, 3, 816-821, https://doi.org/10.1038/nclimate1911, 2013.

Hurst, H. E.: Long-term storage capacity of reservoirs, Transactions of the American Society of Civil Engineering, 116, 770-799, 1951.

IWM: Updating and validation of North West Region Model (NWRM), Institute of Water Modelling, Bangladesh, 2006.

Klemes, V.: Storage mass-curve analysis in a systems-analytic perspective, Water Resources Research, 15, 359-370, 1979.

Kikkawa, H. and Takeuchi, K.: Characteristics of Drought Duration Curve and its Application, Proc. JSCE, 234, 61-71, 1975 (in Japanese).

Lehner, B., Verdin, K., and Jarvis, A.: HydroSHEDS technical documentation v1.0, World Wildlife Fund US, Washington, D.C., 1-27, 2006.

Lehner, B., Liermann, C. R., Revenga, C., Vörösmarty, C., Fekete, B, Crouzet, P., Döll, P., Endejan, M., Frenken, K., Magome, J., Nilsson, C., Robertson, J., Rödel, R., Sindorf, N., and Wisser, D.: High-resolution mapping of the world's reservoirs and dams for sustainable river-flow management, Front. Ecol. Environ., 9, 494-502, 2011.

Maass, A., Hufschmidt, M. M., Dorfman, R., Thomas, H. A., Marglin, S. A., and Fair, G. M.: Design of water-resource systems, Harvard Univ. Press, Cambridge, Mass., USA, 1962.

Magome, J., Gusyev, M. A., Hasegawa, A., and Takeuchi, K.: River discharge simulation of a distributed hydrological model on global scale for the hazard quantification, Proc. 21st International Congress on Modelling and Simulation (MODSIM2015), Broadbeach, Queensland, Australia, 2015, 1593-1599, ISBN: 978-09872143-5-5, 2015.

Mandelbrot, B. B. and Wallis, J. R.: Computer experiments with fractional Gaussian noises: Part 2, rescaled ranges and spectra, Water Resour. Res., 5, 242-259, 1969.

Masood, M. and Takeuchi, K.: Climate Change Impact on the Manageability of Floods and Droughts of the Ganges-BrahmaputraMeghna Basins Using Flood Duration Curves and Drought Duration Curves, J. Disaster Research, 5, 991-1000, 2015a.

Masood, M. and Takeuchi, K.: Persistence Characteristics of Floods and Droughts of the Ganges-Brahmaputra-Meghna Basins Using Flood Duration Curve and Drought Duration Curve, J. Water Resource and Hydraulic Engineering, 4, 413-421, $2015 \mathrm{~b}$.

Masood, M., Yeh, P. J.-F., Hanasaki, N., and Takeuchi, K.: Model study of the impacts of future climate change on the hydrology of Ganges-Brahmaputra-Meghna basin, Hydrol. Earth Syst. Sci., 19, 747-770, https://doi.org/10.5194/hess-19-747-2015, $2015 \mathrm{c}$.

Masutani, K. and Magome, J.: An Application of Modified Muskingum-Cunge Routing Method with Water Conservation Condition to a Distributed Runoff Model, J. Japan Soc. Hydrol and Water Res., 22, 294-300, 2009.

Mirza, M. M. Q.: Global warming and changes in the probability of occurrence of floods in Bangladesh and implications, Global Environ. Chang., 12, 127-138, 2002.

Moran, P. A. P.: The theory of storage, John Wiley \& Sons, Inc., New York, 1959.

Nash, J. E. and Sutcliffe, J. V.: River flow forecasting through conceptual models part I - a discussion of principles, J. Hydrol., 10, 282-290, 1970 .

Pfly: Ganges-Brahmaputra-Meghna basins available at: http: //en.wikipedia.org/wiki/File:Ganges-Brahmaputra-Meghna_ basins.jpg\# (last access: February 2017), 2011.

Rippl, W.: The capacity of storage-reservoirs for water-supply, Minutes Proc. Inst. Civil Eng., 71, 270-278, 1883.

Sevat, E. and Dezetter, A.: Selection of calibration objective functions in the context of rainfall-runoff modeling in a Sudanese savannah area, Hydrolog. Sci. J., 36, 307-330, 1991.

Takeuchi, K.: Chance-constrained Model for Real-time Reservoir Operation Using Drought Duration Curve, Water Resour. Res., 22, 551-558, 1986.

Takeuchi, K.: Hydrological Persistence Characteristics of Floods and Droughts - Interregional comparisons, J. Hydrol., 102, 4967, 1988.

Takeuchi, K. and Kikkawa, H.: Drought Duration Curve Method as Compared with Mass Curve Method, P. JSCE, 303, 53-63, 1980 (in Japanese).

Takeuchi, K., Ao, T., and Ishidaira, H.: Introduction of block-wise use of TOPMODEL and Muskingum-Cunge method for the hydroenvironmental simulation of a large ungauged basin, Hydrolog. Sci. J., 44, 633-646, 1999. 
Takeuchi, K., Hapuarachchi, H. A. P., Zhou, M., Ishidaira, H., and Magome, J.: A BTOP model to extend TOPMODEL for distributed hydrological simulation of large basins, Hydrol. Process., 22, 3236-3251, 2008.

Takeuchi, K., Hapuarachchi, H. A. P., Kiem, A. S., Ishidaira, H., Ao, T. Q., Magome, J., Zhou, M. C., Georgievski, M., Wang, G., and Yoshimura, C.: Distributed runoff predictions in the Mekong River basin, in: Run-off Prediction in Ungauged Basins, Synthesis across Processes, Places and Scales, edited by: Blöschl, G., Sivapalan, M., Wagener, T., Viglione, A., and Savenije, H., Cambridge University Press, 349-352, 2013.

Tateishi, R., Hoan, N. T., Kobayashi, T., Alsaaideh, B., Tana, G., and Phong, D. X.: Production of Global Land Cover Data - GLCNMO2008, J. Geogr. Geol., 6, 99-122, https://doi.org/10.5539/jgg.v6n3p99, 2014.

Thomas, H. A. and Fiering, M. B.: Mathematical synthesis of streamflow sequences for the analysis of river basins by simulation, in: Design of water-resource systems, chap. 12, edited by: Maass, A., Hufschmidt, M. M., Dorfman, R., Thomas Jr., H. A., Marglin, S. A., and Fair, G. M., Harvard Univ. Press, Cambridge, Mass., USA, 1962.
Valencia, D. and Schaake, J. C.: Disaggregation processes in stochastic hydrology, Water Resour. Res., 9, 211-219, 1973.

Weedon, G. P., Gomes, S., Viterbo, P., Österle, H., Adam, J. C., Bellouin, N., Boucher, O., and Best, M.: The watch forcing data 1958-2001: a meteorological forcing dataset for land surface and hydrological models, WATCH Technical Report No. 22, 1-41, 2010.

Weedon, G. P., Gomes, S., Viterbo, P., Shuttleworth, J., Blyth, E., Österle, H., Adam, J. C., Bellouin, N., Boucher, O., and Best, M.: Creation of the WATCH Forcing Data and its use to assess global and regional reference crop evaporation over land during the twentieth century, J. Hydrometeorol., 12, 823-848, 2011.

Wood, E. F., Sivapalan, M., Beven, K., and Band, L.: Effects of spatial variability and scale with implications to hydrologic modelling, J. Hydrol., 102, 29-47, 1988. 